\title{
Intra-urban Microclimate Investigation in Urban Heat Islands: A Novel Experimental Transect Monitoring and Startup Findings from Implementation in Historical City
}

Kousis loannis

University of Perugia

ilaria pigliautile

University of Perugia

Anna Laura Pisello ( $\sim$ anna.pisello@unipg.it )

University of Perugia

\section{Research Article}

Keywords: urban microclimate, microclimatic monitoring, mobile weather station, urban climate, intraurban variations

Posted Date: December 17th, 2020

DOI: https://doi.org/10.21203/rs.3.rs-122544/v1

License: (c) (1) This work is licensed under a Creative Commons Attribution 4.0 International License.

Read Full License 


\title{
Intra-urban microclimate investigation in urban heat islands: a novel experimental transect monitoring and startup findings from implementation in historical city
}

\author{
I. Kousis ${ }^{1}$, I. Pigliautile ${ }^{1,2}$, A.L. Pisello ${ }^{1,2^{*}}$ \\ ${ }^{1}$ CIRIAF - Interuniversity Research Center, University of Perugia. Via G. Duranti $67-$ \\ 06125 - Perugia (Italy) \\ ${ }^{2}$ Department of Engineering - University of Perugia. Via G. Duranti 97 - 06125 - \\ Perugia (Italy) \\ * Corresponding author email address: anna.pisello@unipg.it
}

\begin{abstract}
Monitoring microclimate variables within cities with high accuracy is an ongoing challenge for a better urban resilience to climate change. Assessing the intra-urban characteristics of a city is of vital importance for ensuring fine living standards for citizens. Here, a novel mobile microclimate station is applied for monitoring the main microclimatic variables regulating urban environment as well as directionally monitoring shortwave radiation and illuminance and hence evaluate the effect of urban surfaces and anthropogenic heat. We performed day-time and evening-time monitoring campaigns within a historical city in Italy, characterized by substantial urban structure differentiations. We found significant intra-urban variations concerning variables such as air temperature and shortwave radiation. Moreover, the proposed experimental framework may capture, for the very first time, significant directional variations with respect to Shortwave radiation and illuminance across the city at microclimate scale. The presented mobile station represents therefore the key missing piece for exhaustively identifying urban environmental quality and data driven modelling toward risk and resilience planning. It can be therefore used in combination with satellite data, stable weather station or other mobile stations, e.g. bicycle and wearable sensing techniques, through a citizens' science approach in smart, livable, and sustainable cities in the near future.
\end{abstract}

Keywords: urban microclimate, microclimatic monitoring, mobile weather 
station, urban climate, intra-urban variations

\section{Introduction}

Within recent decades the rural-to-urban population flow has substantially increased. For instance, in 2016, 54\% of the world population was living in urbanised areas. Future projections are even more sinister. It is expected that in 2050 and 2100 the corresponding fraction will increase up to $66 \%$ and $85 \%$ respectively [1]. Urbanization is typically followed by high population and building density and consequent land-use and surface alterations, e.g. scarcity of green areas [2, 3]. Natural-to-urban land alterations affect in turn the local energy balance of cities and thus their microclimatic characteristics and thermal environment in particular [4, 5. As a result, cities tend to systematically experience higher surface and air temperatures as compared to the surrounding rural areas, a phenomenon known as Urban Heat Island (UHI) effect [6-8]. The driving physics behind UHI are the reduction in latent heat flux and increase in sensible heat flux [9, 10]. UHI is a significant human-induced environmental change that poses threats to human life. For instance, increased morbidity and mortality [11], indoor/outdoor discomfort [12, air pollution [13, 14], increased energy consumption [15] and greenhouse gas emissions [16, 17], impaired air and water quality [18] and intensification of energy poverty on vulnerable social groups during the hot months of the year [19, 20] are just some of UHI consequences that usually are interconnected. Also, UHI is associated to the global warming and moreover has been found to synergistically act with heatwaves and amplify their impacts [21 23]. Considering the projections linked to the ongoing climate change, livability of cities will be seriously endangered [24]. In fact, global warming is expected to reach up to $1.5{ }^{\circ} \mathrm{C}$ above pre-industrial levels by 2050 , and up to $2.0-$ $4.9{ }^{\circ} \mathrm{C}$ by 2100 as compared to 1861 - 1880 [25, 26]. Thus, heat related risk within urban canopy layers is likely to increase even more in the very near future making urban population particularly vulnerable during periods of hot weather.

Consequently, measures for counterbalancing UHI and its aftermaths are deemed of critical importance. As a result, techniques for controlling the variables regulating the urban microclimate are receiving increased attention from academics, urban planners and policy-makers [27 29]. Quantifying, however, the magnitude of each microclimatic parameter is not trivial. Instead, 
due to the complex morphology of urban areas, microclimatic conditions have been found to significantly vary not only within different cities but also within different locations of the very same city. For instance, UHI incidences has been found not only between urban and rural areas but also between urban and suburban areas [30, 31]. In general, the profile of each investigated urban microclimate is determined by the unique characteristics of the corresponding area. Therefore, urban microclimate and its intrinsic disomogeneity needs to be in-depth investigated together with its causes and effects with respect to the spatial and temporal variations originated from the specific local morphology, anthropogenic action, urban planning and temporal weather conditions [32 34]. Therefore, for precisely determining the gradient and the inner-city deviations of microclimatic variables, their spatial extent needs to be thoroughly delineated. Mapping out each variable's footprint can result to a better understanding and evaluation of cities' function. At he same time, biases concerning location-wise momentum of investigated variables, UHI magnitude and so forth, will be decreased. Furthermore, more efficient comparison analysis among relevant studies will be feasible [35].

Traditionally, in-situ meteorological stations have been implemented for measuring parameters such as air temperature and humidity, in and out of the city. For instance, Santamouris et al. [36] utilised and retrieved data from a network of 23 experimental weather station within the city of Athens and gauged the corresponding UHI magnitude while the same did Yang et al. [15] in the city of Nanjing, China by implementing a network of 15 weather stations. Results of such type of studies are of critical importance since not only reveal an important issue, i.e. UHI, but also shed light on the corresponding mechanisms of urban climate and hence help towards an establishment of efficient countermeasures. However, since in most cases meteorological stations are sparsely located, data retrieved from this method represent a point-wise momentum of each microclimatic variable and not the overall footprint and the corresponding spatial patterns [15].

To overcome this limitation, recent studies employed remote sensing techniques. In fact, land surface temperature (LST) data from satellites have been widely utilised for measuring the magnitude of microclimatic variables determining surface UHI mainly due to their high spatial resolution. For example several studies used MODIS LST data [37, 38] for assessing UHI and its drivers within high populated cities in China. However, due to their typically low temporal resolution, together with lack of direct air temperature profiles, data retrieved from satellites cannot be used for evaluating an 
extensive intra-urban distribution of UHI.

Under this framework, mobile meteorological units, placed typically on motorized vehicles, are becoming popular among academics for determining the spatial variability of microclimatic variables within a city. Table 1 gives a brief overview of relevant published scientific works. Unlike fixed units, mobile stations can offer data acquisition of higher temporal and spatial resolution within the desired urban context and thus can be used for identifying the intra-urban diversifications of the parameters affecting the urban microclimate and consequently human well-being. For instance, Hart and Sailor [39] utilised vehicular temperature traverses in order to determine spatial variability of air temperature at two meter height across the metropolitan area of Portland, US. Santamouris et al. [40] developed a mobile weather station on a telescopic mast placed atop of a vehicular van capable of measuring air temperature, wind speed and direction at different heights with time-step of $30 \mathrm{~s}$ and performed monitoring campaign before and after the implementation of cool pavements in an urban park at the city of Athens, Greece. Similarly, Busato et al. [30] assessed UHI incidences within the city of Padua, Italy through the development and utilisation of a mobile weather station built on a vehicle and capable to measure air temperature, relative humidity and solar global radiation with a time-step of $5 \mathrm{~s}$. Mobile weather units were employed also in the study of Parece et al. [41] aiming to capture spatial patterns of air temperature (2 s time-step) across the Roanoke, Virginia, USA. Santamouris et al. [42] also developed a mobile weather station, called "EnergyBus", the measures air temperature, relative humidity, pressure and wind speed.

Moreover, mobile weather stations have been also developed on humanwearable helmet [32] and trolleys [53] in order to monitor pedestrian pathways and the corresponding thermal comfort. Nevertheless, areas of vehicular traffic dominate typically the outdoor urban environment [54]. Hence understanding the differing and localized patterns of the parameters that regulate the corresponding microclimate through an analytical monitoring is of primary importance. That said, both temporary effect variables, such as temperature, humidity, wind speed and direction, and permanent effect variables, such as materials implemented into built environment, must be taken into consideration. Subsequently, thermal environment and comfort can be efficiently accessed and evaluated for safeguarding well-being of the citizens.

Under this framework, this study aims to contribute towards exhaustive non-static monitoring techniques that can identify environmental quality of urban areas and hence safeguard fine standards of the corresponding risk 
Table 1: Studies with mobile traverse monitoring methods. $\mathrm{T}_{\text {air }}$ is air temperature, $\mathrm{RH}$ is relative humidity, WS and WD are wind speed and direction, SR and LR are short-wave and long-wave incident radiation, $\mathrm{P}$ is pressure, $\mathrm{E}_{v}$ is illuminance, $\lambda$ is Longitude, $\phi$ is latitude, $\mathrm{h}$ is altitude and $\mathrm{dr}$ is precipitation.

\begin{tabular}{lllllll} 
Study & Year & Type & Variables & City & Scale & Access \\
\hline \hline 43$]$ & 1998 & $\begin{array}{l}\text { automobile, } \\
\text { bicycle }\end{array}$ & $\mathrm{T}_{\text {air }}$ & $\begin{array}{l}\text { Vancouver, CA } \\
\text { Sacramento, US }\end{array}$ & $\begin{array}{l}\text { macro, } \\
\text { micro }\end{array}$ & roadways, \\
pedestrians
\end{tabular}

and resilience planning. It presents the application of an advanced mobile weather station within a city of central Italy. The mobile station can monitor profiles of the main parameters that regulate the lower levels of a typical urban canopy layer. More specifically, it can monitor not only scalar or vector variables such as air temperature, humidity, wind profile and air pollutants' concentration, but also directionally dependent variables, such as reflected 
and diffused shortwave radiation and illuminance that are typically affected from the properties of urban surfaces. The start-up of the novel methodology is demonstrated through two transect campaigns during the winter period of 2020 within the historical city of Perugia, Italy. The main variables that define the quality of a typical urban environment were subsequently mapped and evaluated in terms of intra-urban variations within districts of different morphology.

\section{Results and Discussion}

Two monitoring campaigns were devised and carried out from the authors during the months of January and February of 2020, i.e. in winter conditions in terms of weather. Previous studies showed that correlations between microclimate parameters and urban morphology are more accurate in terms of statistical significance during clear sky conditions and generally stable boundary conditions [32]. Hence, one clear sky day-time and one clear sky evening-time days were chosen for carrying out the presented monitoring campaigns (Table 2).

Table 2: Monitoring days and their abbreviation.

\begin{tabular}{ccccc} 
Monitoring day & Time of the day & Start-time & End-time & Abbreviation \\
\hline \hline $23 / 01 / 2020$ & day-time & $12: 34$ & $13: 27$ & day 1 \\
$13 / 02 / 2020$ & evening-time & $17: 49$ & $19: 02$ & day 2 \\
\hline
\end{tabular}

Both monitoring campaigns followed the very same pathway within the city of Perugia, in central Italy. According to the Köppen and Geiger classification, Perugia is classified as Cfa and is characterized by humid subtropical climate conditions [55]. The pathway (Fig. 1) is almost circular and ends where it starts. It is specifically planned to pass through and monitor areas characterized by different types of (i) urban morphology, (ii) land-use, and (iii) human activity. In fact, the pathway crosses three significantly different areas: (i)the main suburb area of Perugia, (ii) the recent urban neighborhood close to the main train station and (iii) the center area of the city. In order to get a significant spatial resolution, vehicle speed was maintained around $20 \mathrm{~km} / \mathrm{h}$ and hence measurements were taken approximately every $50 \mathrm{~m}$. Further details of each area can be found on Table 3 . 


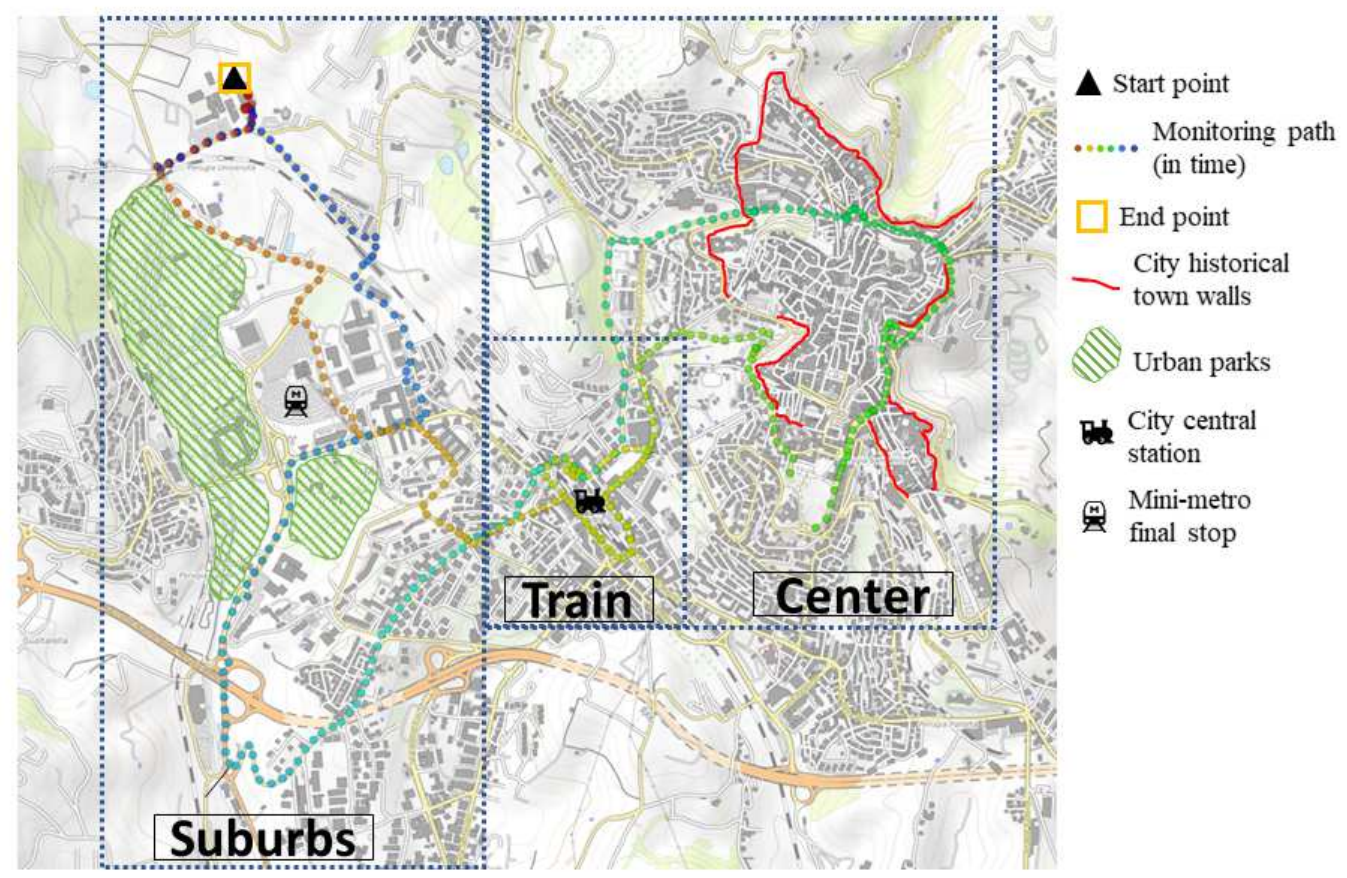

Figure 1: Pathway of monitoring campaigns.

Table 3: Clustered areas' details.

\begin{tabular}{ccc} 
Clustered area & Coverage in progressive distnace $[\mathrm{m}]$ & abreviation \\
\hline \hline suburbs & $0-4600$ & Suburbs-1 \\
train & $4600-7900$ & Train-1 \\
center & $7900-14100$ & Center \\
train & $14100-15300$ & Train-2 \\
suburbs & $15300-$ end & Suburbs-2 \\
\hline
\end{tabular}

\subsection{Boundary Conditions}

At first, data derived from a stable weather station built on the roof of University of Perugia [56] were retrieved for defining the boundary conditions of each monitoring campaign in terms of air temperature and shortwave radiation. As it can be seen on Fig. 2, profiles of air temperature are rather similar for both days. The mean air temperature values are $4.5^{\circ} \mathrm{C}$ and $7.4{ }^{\circ} \mathrm{C}$ concerning day-1 and day-2, respectively. The maximum value of incoming shortwave radiation was $617 \mathrm{~W} / \mathrm{m}^{2}$ for day-1 and $609 \mathrm{~W} / \mathrm{m}^{2}$ for day-2. 

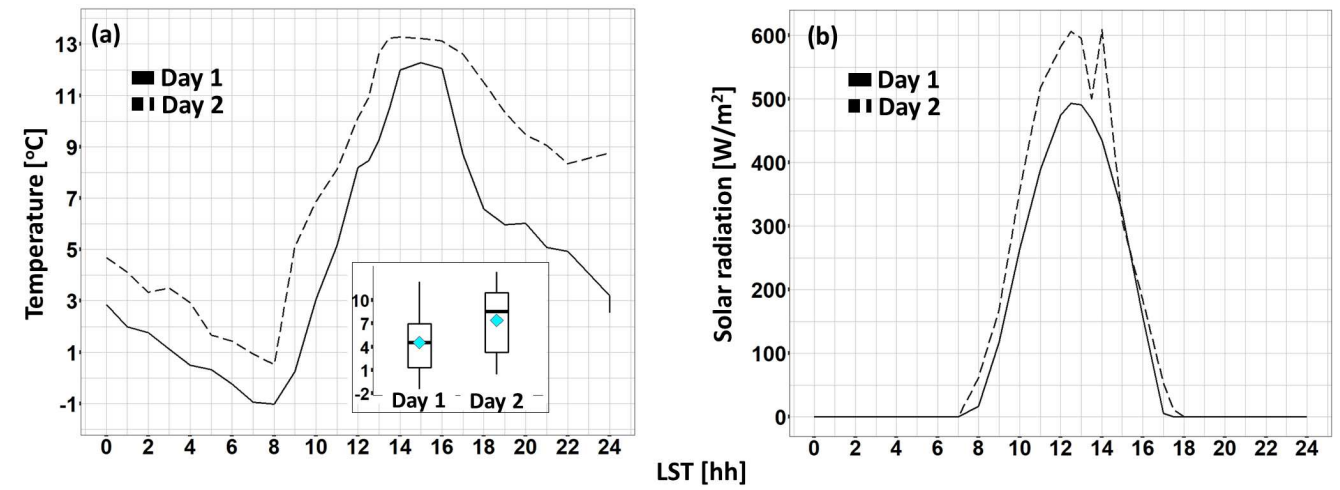

Figure 2: (a) $24 \mathrm{~h}$ air temperature profile for both day-1 and day-2, (b) $24 \mathrm{~h}$ solar global radiation profile for both day- 1 and day- 2

\subsection{Overview of the experimental data}

Figure 3 illustrates the probability density and the central tendency of the monitored variables during the campaigns. Air temperature within day-1 is distributed approximately from 8 to $12{ }^{\circ} \mathrm{C}$ with a mean value equal to $9.9^{\circ} \mathrm{C}$, while on day-2 air temperature is distributed from 10 to $13.4^{\circ} \mathrm{C}$ with a mean value equal to $12.1^{\circ} \mathrm{C}$. Temperature values were slightly higher during evening-time monitoring campaigns due to the imminent conclusion of winter period. Absolute humidity profile of day-2 was slightly wider than the one of the day- 1 with corresponding mean values equal to $6.9 \mathrm{~g} / \mathrm{m}^{3}$ and $6.3 \mathrm{~g} / \mathrm{m}^{3}$ respectively. The distributions of air pollutants, i.e. $\mathrm{CO}_{2}$ and PM10, can be seen on Fig. 3. The widest distribution as well as the highest values concerning both $\mathrm{CO}_{2}$ and PM10 occurred on day-1, most likely due to higher vehicular traffic and other human induced activities that take place more frequently during the daytime. The corresponding mean values are $484 \mathrm{ppm}$ and $56 \mathrm{ppm}$ concerning $\mathrm{CO}_{2}$ and PM10 respectively. During day-2 $\mathrm{CO}_{2}$ concentration is distributed within $413-477 \mathrm{ppm}$ with a mean value equal to $443 \mathrm{ppm}$ while PM10 concentration varies within 2-21 ppm with a mean value equal to $9 \mathrm{ppm}$. Shortwave radiation values during day-1 followed a rather wide distribution owing to urban morphology variations. In fact, shortwave radiation is distributed from 11 to $496 \mathrm{~W} / \mathrm{m}^{2}$ with a mean value equal to 196 $\mathrm{W} / \mathrm{m}^{2}$. A slightly narrower distribution is observed concerning illuminance during day-2, with values varying from 229 to 347 lux and a mean value equal to 274 lux. 

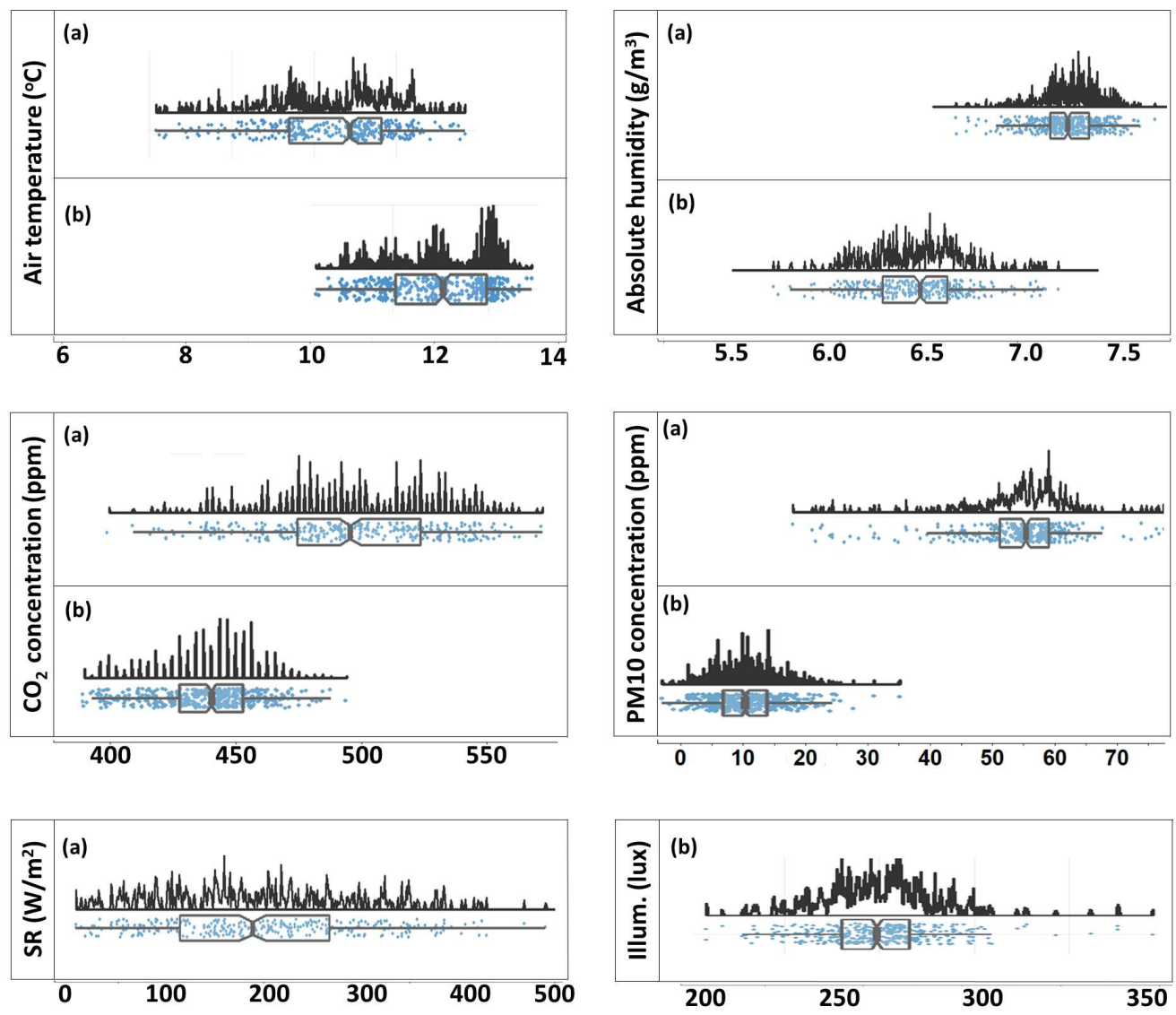

Figure 3: Variables' distribution.(a) day 1, (b) day 2.

A further investigation of possible primary relationships among the measured microclimate variables was performed through Pearson's correlation analysis, since almost all variables follow the normal distribution. The corresponding results are illustrated on Fig. 4. Within the diagonal of each matrix, histograms with kernel density estimations and the corresponding rug plots can be seen for each correlated couple. Within the upper part of the diagonal, the corresponding correlation coefficients (r), i.e. the strength of the relationship, are depicted together with the p-value, i.e. the statistical significance of the relationship. Within the lower part of the diagonal scatter plots of each correlated couples are illustrated together with fitted lines and ellipses for displaying the strength of the relationship. 
During day-time monitoring campaign the most significant relationship was positive and found for air temperature and altitude, i.e. $\mathrm{r}=.62, \mathrm{p}<.001$. Other noteworthy relationships were found for absolute humidity and Shortwave radiation $(\mathrm{r}=.74, \mathrm{p}<.001)$, and altitude and PM10 $(\mathrm{r}=.46, \mathrm{p}<.001)$. Likewise, primary relationships within the measured variables were moderate to low during evening-time monitoring. A negative primary relationship was observed concerning altitude and air temperature $(\mathrm{r}=-.66, \mathrm{p}<.001)$ on day- 2 . In addition, during the same day a noteworthy positive relationship can be seen for shortwave radiation and $\mathrm{CO}_{2}(\mathrm{r}=.48, \mathrm{p}<.001)$. 

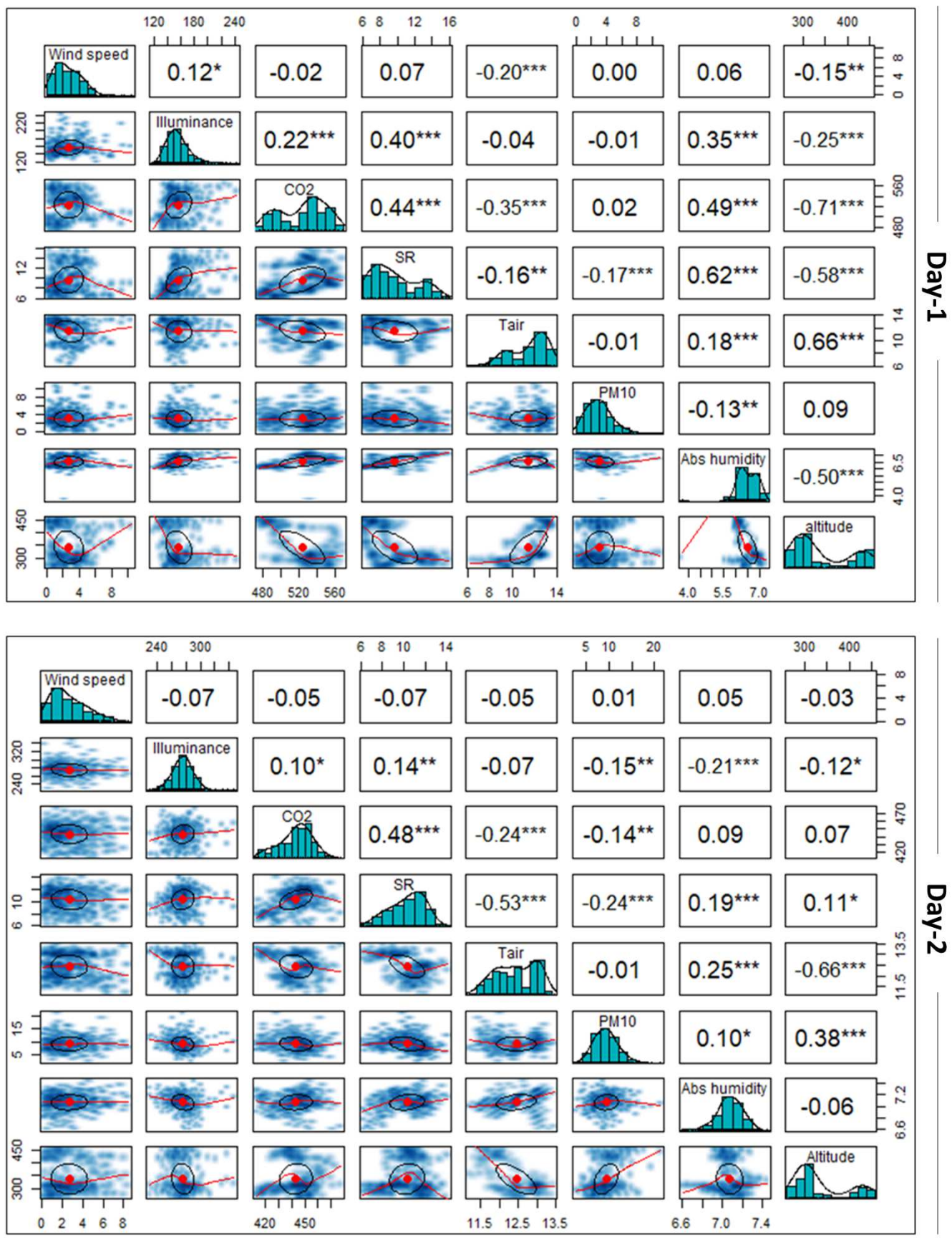

Figure 4: Variable correlation for day-1 and day-2. One star ('*'), Two stars ('**'), Three stars ( $\left.{ }^{* * *}\right)$ denote that the corresponding variable is significant at $10 \%, 5 \%, 1 \%$ level, respectively. Absence of star denotes no significant variable. 


\subsection{Intra-urban profiles of the microclimatic variables}

A representation of intra-urban variations of some of the collected variables can be seen in Fig. 5 where air temperature (images a and d), $\mathrm{CO}_{2}$ (images b and e) and PM10 (images c and f) profiles across the followed monitoring paths are depicted with respect to day-1 and day-2. Moreover, further information is given by varying dot size with respect to the desired variable. Here, the size

of each illustrated circle-point varies with respect to the corresponding relative humidity $(\mathrm{RH})$ and wind speed (WS) values concerning the air temperature and air pollutant images respectively. Through this representation, some elementary outcomes can come out, e.g. that high temperature values occur simultaneously with low values of relative humidity. Also, localized hot-spots with respect to each variable can be identified. For instance, within the monitoring duration of day-1 the highest values of temperature were recorded on the peripheral area of the city center and within the suburbs- 2 area. On the evening hours of day-2, the higher air temperature values were recorded also in the area of railway station and in the center. Similarly the highest values of $\mathrm{CO}_{2}$ and PM10 concentration were recorded mainly at both railway and its neighboring areas especially on day-1. During the monitoring hours of day-2 the atmosphere within the investigated area was rather clear in terms of PM10 concentration.

A more precise picture of the variable profiles can be observed through the illustration of the corresponding time-series. In Fig. 6 the temperature profiles during the two monitoring campaigns are illustrated. A temperature gradient $\left(\Delta \mathrm{T}_{\max } \approx 1.5^{\circ} \mathrm{C}\right)$ can be seen between Train-1 and Center areas within day-1. An adverse but more steady gradient can be seen within day- 2 .

The temperature substantially dropped $\left(\Delta \mathrm{T}_{\max } \approx-1.5^{\circ} \mathrm{C}\right)$ while entering the Center area of the city and substantially increased when approaching Train-2 area $\left(\Delta \mathrm{T}_{\max } \approx 1{ }^{\circ} \mathrm{C}\right)$. During both days, a steep drop and increase of temperature can be spotted within the last meters of Center area. This trend, is more apparent within day-1 and is attributed to a substantial tree coverage within the specific street crossed in that area. Unlike relative humidity, absolute humidity, do not depend on temperature. However, here, a rather stable profile of absolute humidity can be observed during both day-1 $\left(\right.$ Standard deviation $\left.=0.2 \mathrm{~g} / \mathrm{m}^{3}\right)$ and day-2 $\left(\right.$ Standard deviation $\left.=0.1 \mathrm{~g} / \mathrm{m}^{3}\right)$, mainly due to absence of water areas or large green areas. On the other hand, relative humidity typically follows an adverse trend as compared to air temperature. 

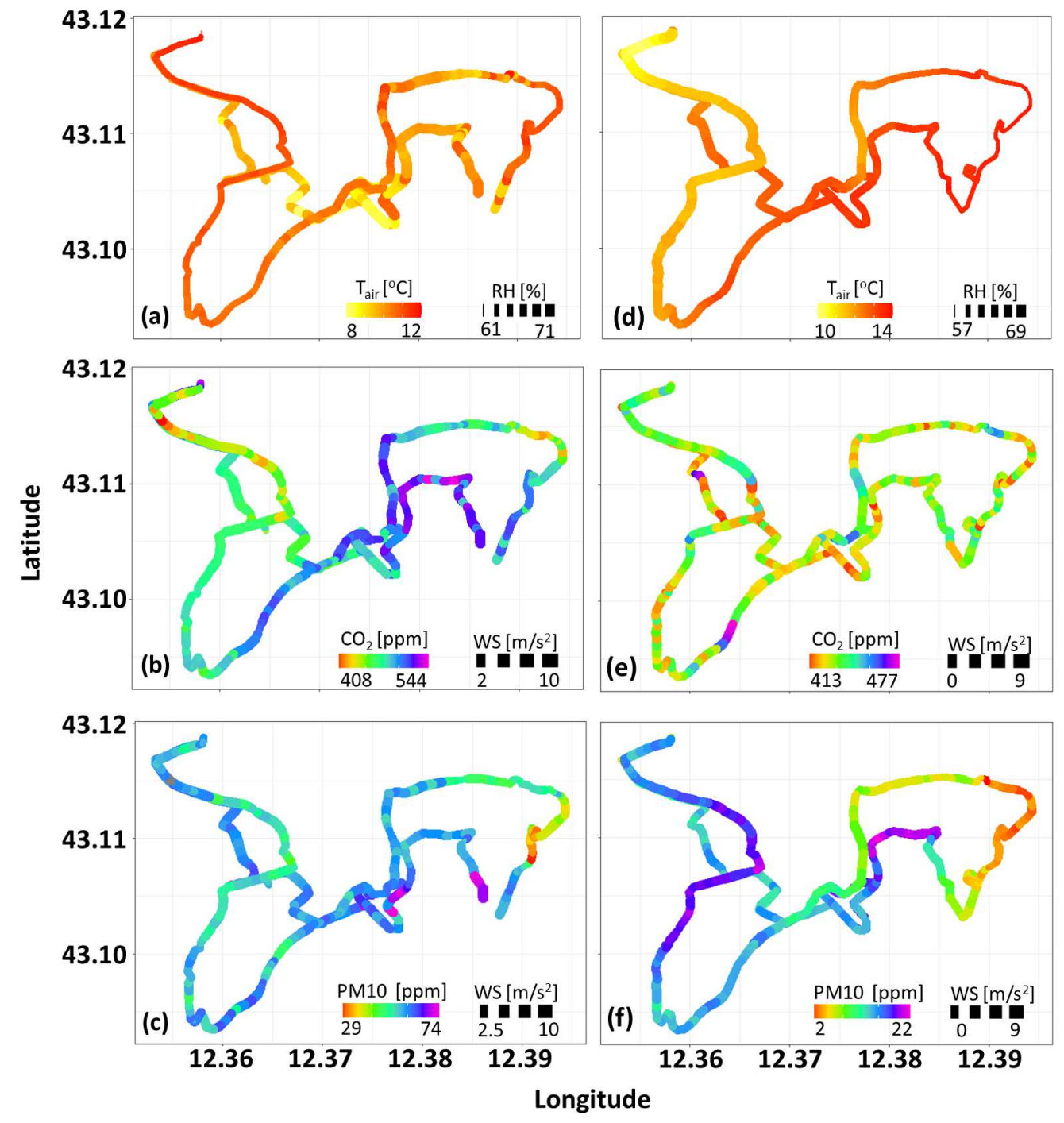

Figure 5: Day-time/Evening-time monitoring. (a) day 1 - air temperature vs. relative humidity, (b) day $1-\mathrm{CO}_{2}$ concentration vs. wind speed, (c) day 1 - PM10 concentration vs. wind speed, (d) day 2 - air temperature vs. relative humidity, (e) day $2-\mathrm{CO}_{2}$ concentration vs. wind speed, (f) day 2 - PM10 concentration vs. wind speed

This is rather obvious in Fig. 7, where a small drop $\left(\Delta \mathrm{RH}_{\max } \approx-3 \%\right)$ and increase $\left(\Delta \mathrm{RH}_{\max } \approx 3 \%\right.$ can be seen within Center area on day-1 and day- 2 respectively. Dewpoint temperature (DT) is alternative way of capturing humidity and comfort and it is regarded as a more accurate metric since it is 
an absolute measurement. During day-1 a significant gradient $\left(\Delta \mathrm{DT}_{\max } \approx\right.$ $0.5^{\circ} \mathrm{C}$ ) towards higher values can be seen as the station was moving from the Center area to the Train-2 one. A rather adverse profile is observed during day-2. Dewpoint temperature decreased as entering into Center area $\left(\Delta \mathrm{DT}_{\text {max }} \approx-0.6{ }^{\circ} \mathrm{C}\right)$ and remained almost stable $\left(\Delta \mathrm{DT}_{\text {mean }} \approx 4.8{ }^{\circ} \mathrm{C}\right)$ up to the end of the campaign.

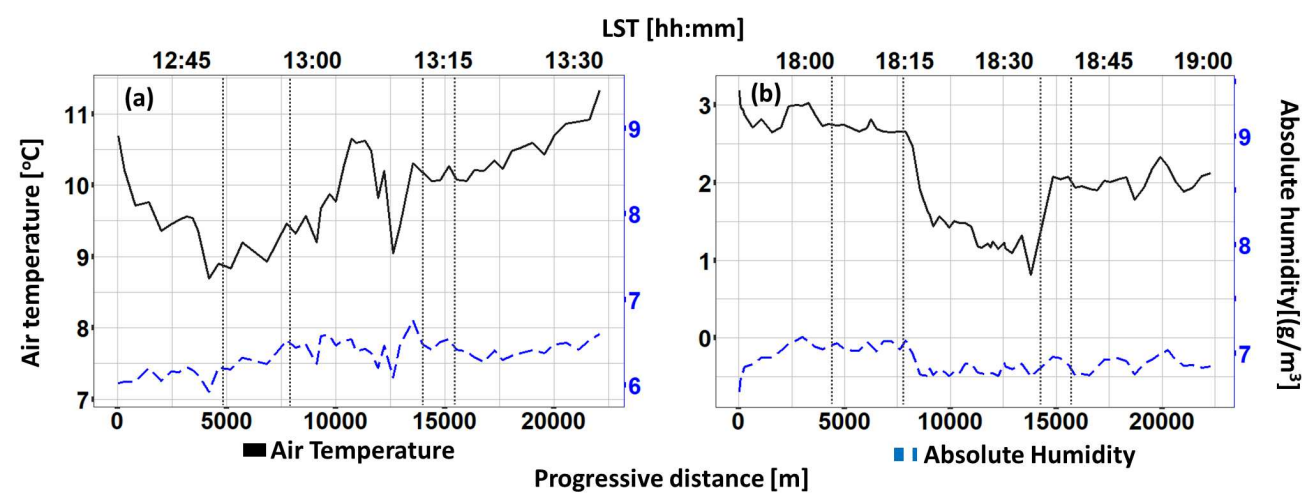

Figure 6: Air temperature and absolute humidity for (a) day 1, (b) day 2 monitoring. Vertical dotted lines stand for the boundaries in-between suburban (first and fifth section), train (second and forth section) and center area of the city.

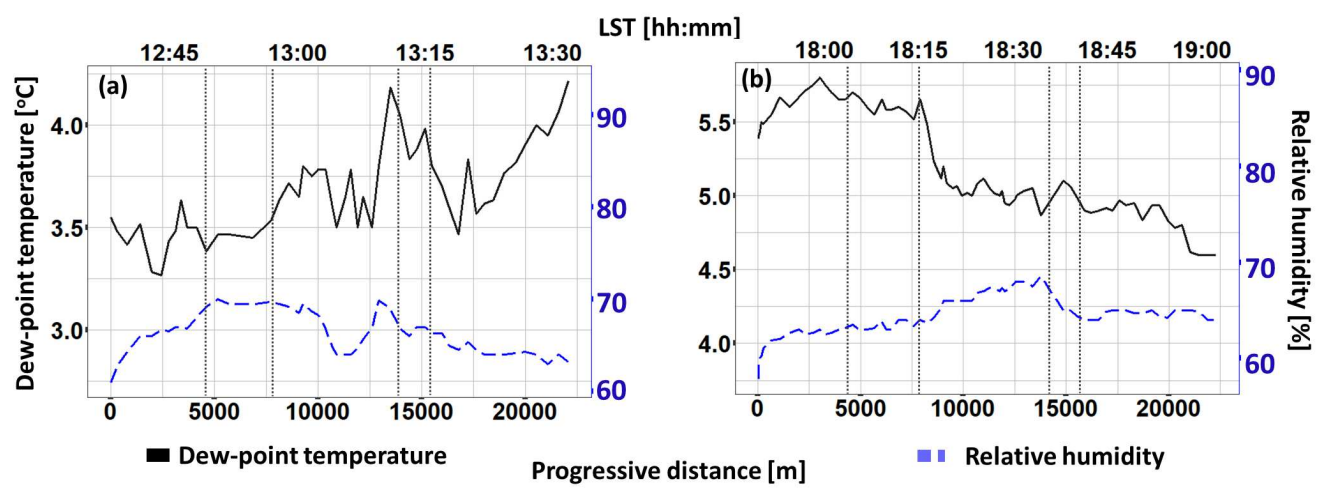

Figure 7: Dew-point temperature and relative humidity (a) day 1, (b) day 2 monitoring. Vertical dotted lines stand for the boundaries in-between suburban (first and fifth section), train (second and forth section) and center area of the city.

Figure 8 shows the concentration levels of $\mathrm{CO}_{2}$ and $\mathrm{PM} 10$, i.e. two key metrics of air pollution within urban microclimate. Concerning $\mathrm{CO}_{2}$, no substantial variations were recorded during both day-1 (Standard Deviation 
$=27.4 \mathrm{ppm})$ and day-2 (Standard Deviation $=12.3 \mathrm{ppm})$ time monitoring campaigns. However, on day-1, a small drop $\left(\Delta \mathrm{CO}_{2 \max } \approx-70^{\circ} \mathrm{ppm}\right)$ of $\mathrm{CO}_{2}$ concentration can be noticed within Center area. At the same day and point a small reduction $\left(\triangle \mathrm{PM} 10_{2 \max } \approx-30{ }^{\circ} \mathrm{ppm}\right)$ can be observed also for PM10 concentration. This drop is likely dew to the physical characteristics of the specific spot. It is an open-air spot and hence wind could locally remove pollutants. Also, a localized and short-term decrease in vehicular traffic might have occurred. Concerning PM10 during day-2, no significant variations were observed (Standard Deviation $=2.7 \mathrm{ppm}$ ).

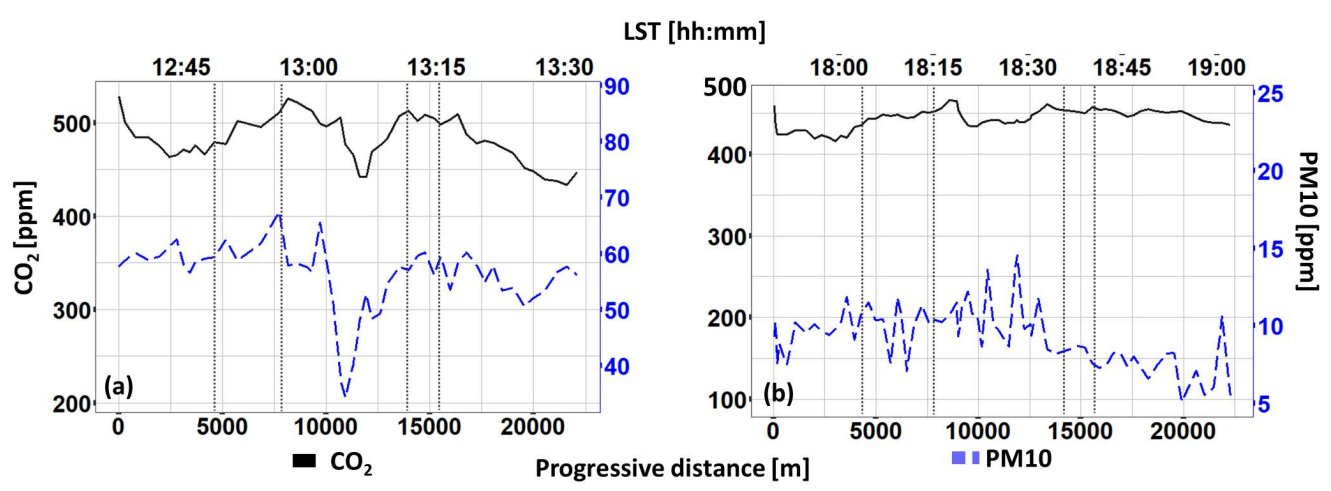

Figure 8: $\mathrm{CO}_{2}$ and PM10 concentration (a) day 1, (b) day 2 monitoring. Vertical dotted lines stand for the boundaries in-between suburban (first and fifth section), train (second and forth section) and center area of the city.

In Fig. 9 the profiles of shortwave radiation and illuminance are presented for day- 1 and day- 2 respectively. The results presented in this figure represent the mean value of the data retrieved from the five sensors for both shortwave radiation and illuminance. Globally speaking, both solar radiation and illuminance are depending on the climatic zone of the investigated area, the time of the year and the overall urban infrastructure. Of course, illuminance is a rather sensitive variable affected by various boundary conditions and hence its values significantly fluctuate around the mean value $\left(\mathrm{E}_{v \max }=347\right.$ lux and $\mathrm{E}_{v \min }=229$ lux). Nevertheless, several peaks can be seen within Train-1, 2 and Center areas where the most anthropogenic activities take place (Fig. 9b). Similar fluctuations were found also concerning shortwave radiation (Fig. 9 ). Overall, shortwave radiation follows a somehow similar profile with air temperature. For example, an increase $\left(\Delta \mathrm{SR}_{\max } \approx 100{ }^{\circ} \mathrm{W} /{ }^{2}\right)$ can be seen as entering Train- 1 zone, while a steep drop up to $205 \mathrm{w} /{ }^{2}$ can 
be seen within Center area when the station turned to a well-shaded street. The highest values were measured within the substantially unshaded areas of Suburbs- 1 and 2.

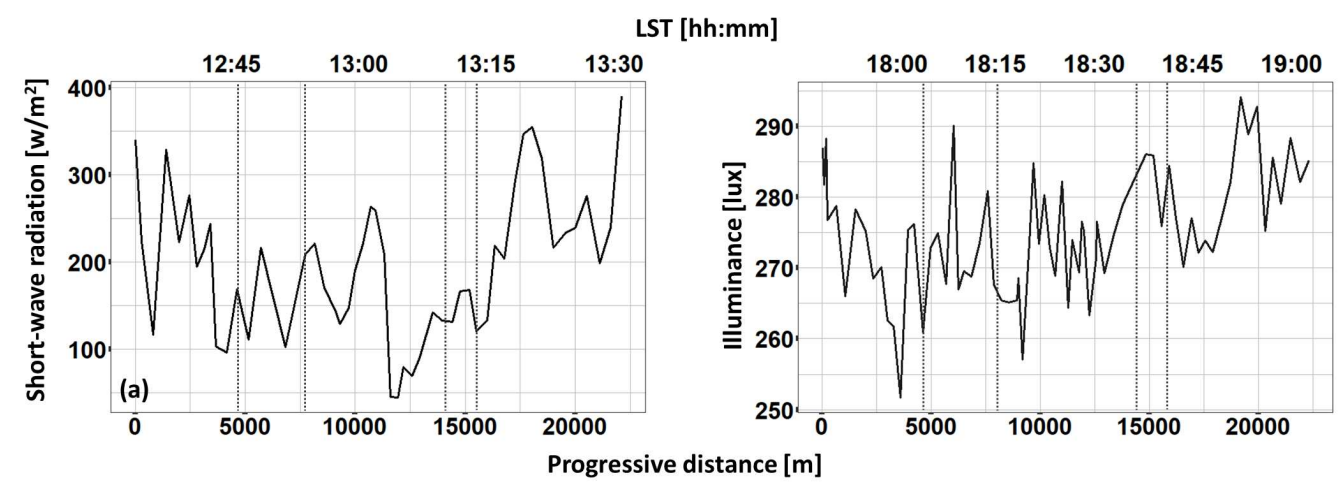

Figure 9: Solar-wave radiation and illuminance (a) day 1, (b) day 2 monitoring. Vertical dotted lines stand for the boundaries in-between suburban (first and fifth section), train (second and forth section) and center area of the city.

Day-1 and 2 were specifically chosen for the presented monitoring campaigns due to their relative stable boundary conditions. As a result, wind speed deviations were rather small (Fig. 10), i.e. the wind speed standard deviations were $2.1 \mathrm{~m} / \mathrm{s}^{2}$ and $1.8 \mathrm{~m} / \mathrm{s}^{2}$ for day-1 and day-2 respectively. Two peaks can be observed as entering and leaving from the Center area owing to the corresponding open air location, while inside the historic walls where the streets are substantially narrower wind speed was lower. Wind direction was in general towards North either North-East $\left(0-90^{\circ}\right)$ or North-West $\left(270-360^{\circ}\right)$. It should be noted that the highest values of wind speed occurred most of the time together with North-East wind.

Figure 11 presents the deviation of air temperature and absolute humidity with respect to the corresponding mean value. Significant deviations have been found concerning air temperature within both monitoring campaigns. For instance, during day-1 deviations ranged from -1.1 to $1.3{ }^{\circ} \mathrm{C}$. The peak negative deviation form the mean value (mean temperature $=9.9^{\circ} \mathrm{C}$ ) was recorded as approaching the Train-1 area while the first positive peak deviation was reported within Center area. Even higher positive peak deviation values were reported within Suburbs-2 area owing to their unshaded and open-air environment. A rather adverse profile can be observed during day-2. The corresponding deviations ranged from -1.0 to $0.8^{\circ} \mathrm{C}$. However, the global 


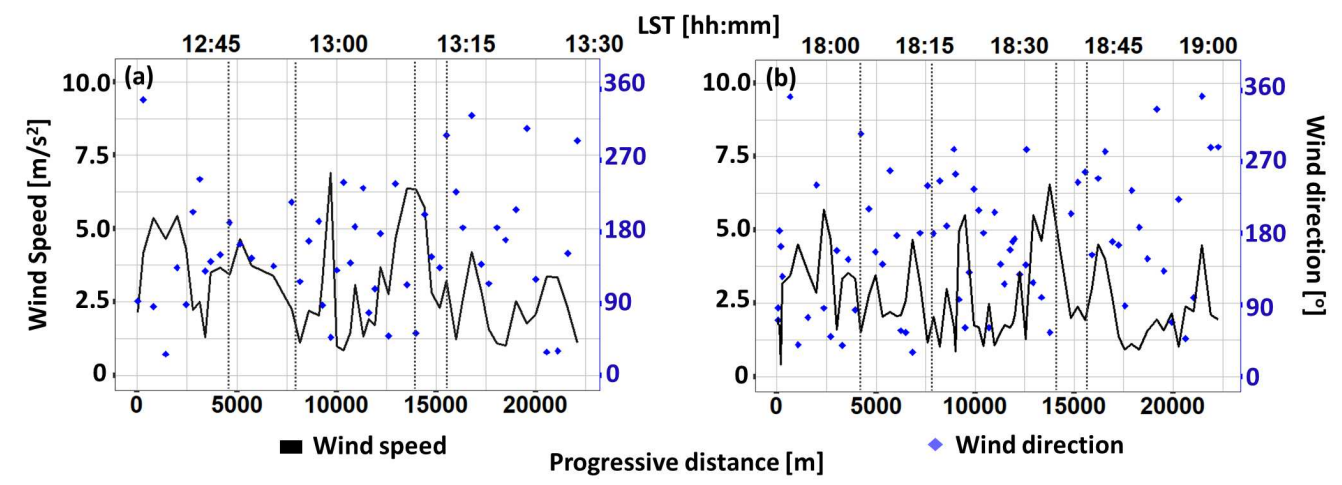

Figure 10: Wind speed and direction (a) day 1, (b) day 2 monitoring. Vertical dotted lines stand for the boundaries in-between suburban (first and fifth section), train (second and forth section) and center area of the city.

positive peak deviation was found for the Train-1 area while the global negative peak was found for Center area. On the other hand, absolute humidity deviations as compared to the average value were found rather low.

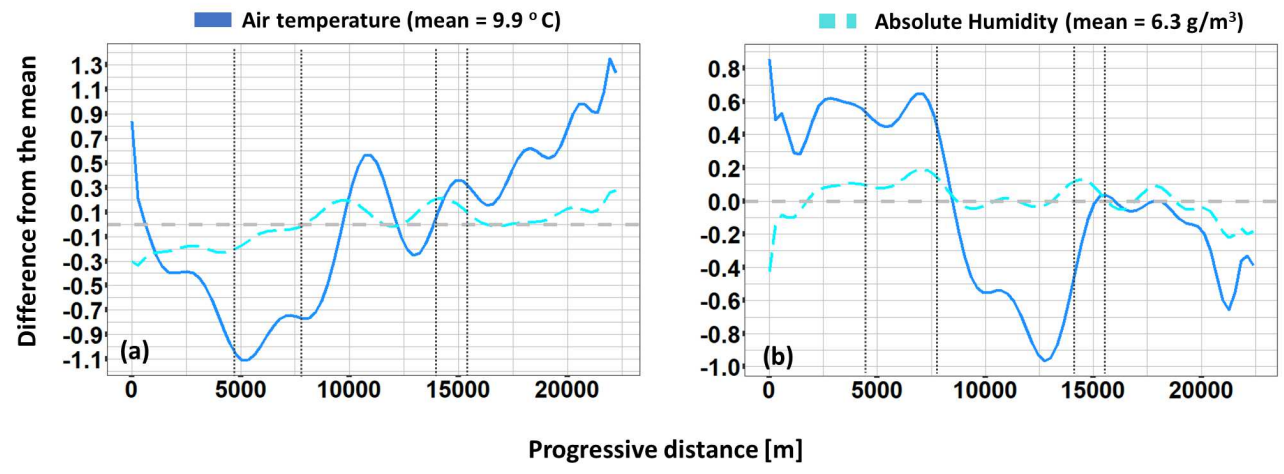

Figure 11: Deviations from the mean value. (a) day 1 - air temperature and absolute humidity, (b) day 2 - air temperature and absolute humidity. Vertical dotted lines stand for the boundaries in-between suburban (first and fifth section), train (second and forth section) and center area of the city.

In Fig. 12 a cluster analysis of the monitoring path can be seen with respect to different areas of the city. The highest values of air temperature during day- 1 were recorded within the suburbs 2 area. Air temperature was slightly lower within Train 2 and Center areas. However, concerning the latter area, the distribution was wider since this area covers a bigger fraction of the 
overall path. Concerning $\mathrm{CO}_{2}$, the higher values were recorded within the Train and Center areas during both monitoring campaigns. A similar trend was found for PM10 during day-2. On the other hand, during day-1, PM10 concentration within the Center area was found slightly lower as compared to the rest areas. In Fig. 13 the directional profile of shortwave radiation (within day-1) and illuminance (day-2) are presented for four different points within the monitoring path. In the suburban areas which typically are more open aired then the center the shortwave radiation varies significantly within 0 to $180^{\circ}$, e.g. at points $\mathrm{A}$ and $\mathrm{D}$. On the other hand, within the center area where the streets are significantly narrower the incident shortwave radiation is more confined in terms of incident angle like in the case of points B $\left(90^{\circ}\right)$ and $\mathrm{C}\left(180^{\circ}\right)$. The directional illustration of illuminace levels for the same four spots showed the main light sources are always on the right side of the station. This is to be expected since day-2 was an evening time monitoring campaign and since Italy is a right lane driving country, the main light sources typically found close to $0^{\circ}$ with respect to the mobile station.
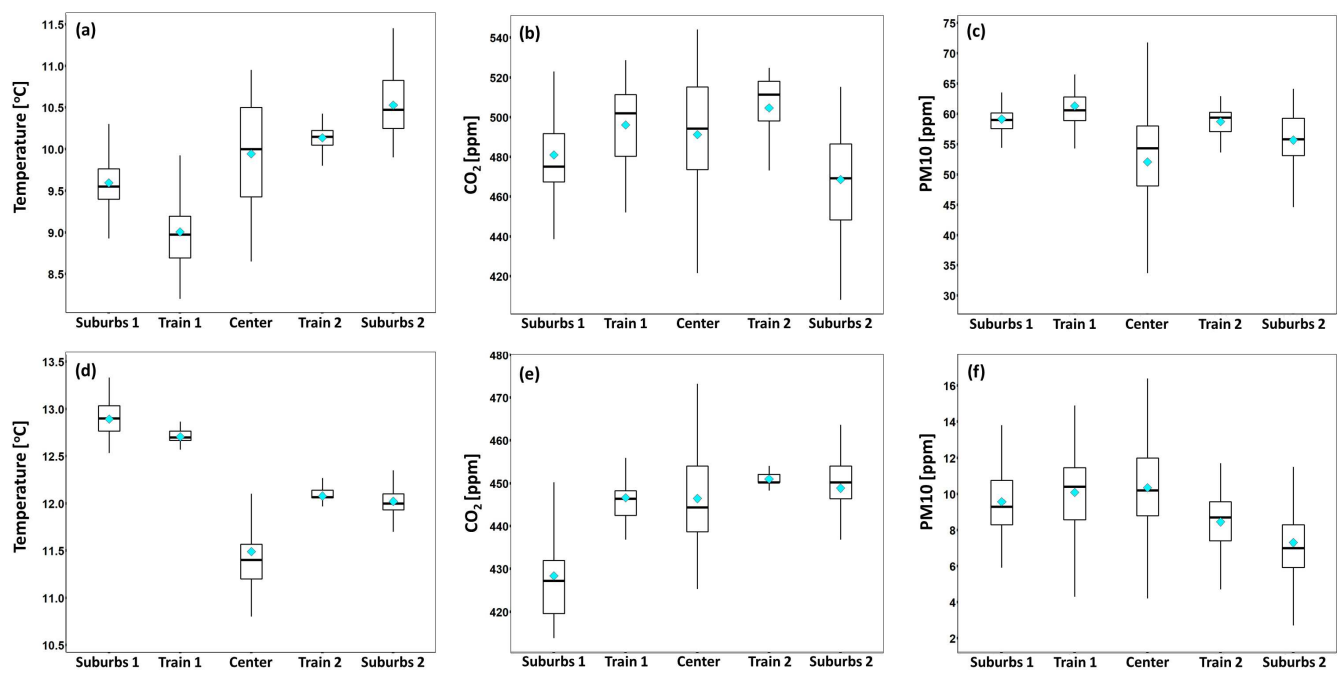

Figure 12: Cluster analysis of air temperature and air pollutants.

\section{Conclusions}

The current study reports on the application of advanced mobile monitoring techniques within a historical lively city of central Italy. A mobile 

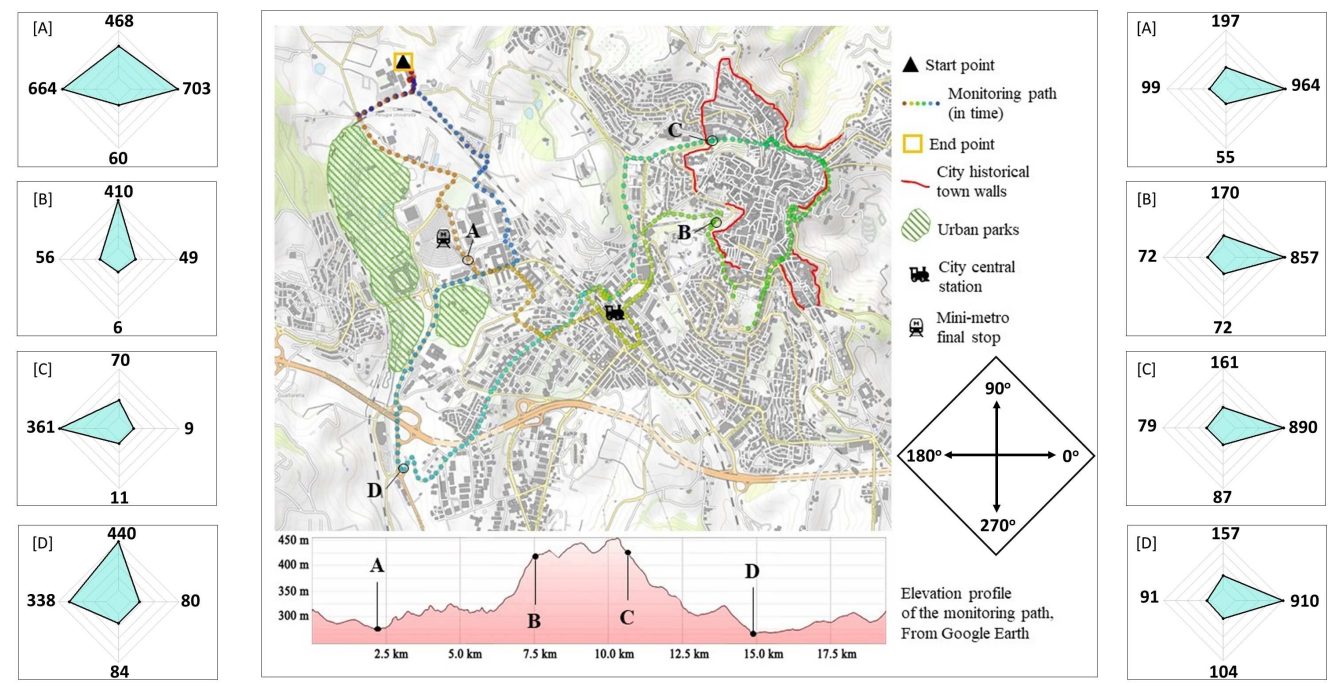

Figure 13: Directional representation of shortwave radiation $\left(\mathrm{w} / \mathrm{m}^{2}-\right.$ left column) and illuminance (lux - right column).

monitoring station is implemented and extensively monitored the main micrometeorological variables that affect climate on city scale, as well as parameters related to urban surfaces. The main stimulus of its development was to gauge and map intra-urban deviations of the main variables determining urban microclimate. Following an observational mobile-transcent methodology, the station can access and monitor almost all areas accessible by car. Unlike mobile monitoring techniques implemented to date on a macro-scale within urban areas, the presented technique succeeds the detailed monitoring of scalar, vector and directionaly dependent variables. A start-up assessment was carried out in central Italy in winter conditions, a period under-reported in particular. Results showed that determinants of urban microclimate and hence quality of urban environment can substantially vary within the very same city (Table 4). Locating hot-spots with respect to each, or combinations, of microclimatic parameters and the corresponding correlation is not trivia. Each city is characterized by its specific peculiarities. Perugia, the city chosen for the present study, is characterized by a diverse morphology. It comprises a city center with narrow and shaded streets with limited vehicular traffic, a more recent neighborhood developed around the main train station with substantial anthropogenic action and several mostly residential suburban areas with open air streets. As a result, shortwave radiation significantly varied 
within different directions during the day-time. A directional dependency was found also for the illuminance levels during evening-time monitoring. Overall, the outcomes of the study represent a key missing piece for a state-of-the-art characterization of urban environmental quality. Their further evaluation under the framework of a wide monitoring network comprising satellite and stable weather station data or other mobile stations, e.g. bicycle and wearable sensing techniques, can contribute towards effective data-driven decision making policies with respect to risk and resilience planning.

Table 4: Maximum variations of monitored variables.

\begin{tabular}{cccccccc}
$\begin{array}{l}\text { Air } \\
\text { Temperature } \\
\left({ }^{\circ} \mathrm{C}\right)\end{array}$ & $\begin{array}{l}\text { Absolute } \\
\text { Humidity } \\
\left(\mathrm{g} / \mathrm{m}^{3}\right)\end{array}$ & $\begin{array}{l}\mathrm{CO}_{2} \\
\text { concentration } \\
(\mathrm{ppm})\end{array}$ & $\begin{array}{l}\text { Pm10 } \\
\text { concentration } \\
(\mathrm{ppm})\end{array}$ & $\begin{array}{l}\text { Solar } \\
\text { Radiation } \\
\left(\mathrm{w} / \mathrm{m}^{2}\right)\end{array}$ & $\begin{array}{l}\text { Illumi- } \\
\text { nance } \\
(\mathrm{lux})\end{array}$ & $\begin{array}{l}\text { Wind } \\
\text { Speed } \\
\left(\mathrm{m} / \mathrm{s}^{2}\right)\end{array}$ \\
\hline \hline day-1 & 3.2 & 1.3 & 136 & 45 & 484.1 & - & 12.3 \\
day-2 & 2.3 & 0.8 & 64 & 19 & - & 118 & 8.3 \\
\hline
\end{tabular}

\section{Methods}

The mobile monitoring station comprises four units of sensors equipped on the 3D surface of the vehicle (Fig. 14). Sensors' proper function is ensured by positioning them on the top and back facades of the vehicle so as to minimize both external interferences, e.g. shading effects, and overlapping incidences. Also, in order to minimize possible affections originated from the van surface all units are placed above a specifically designed wooden base. The variables measured by the mobile station are air temperature, relative humidity, solar global radiation, illuminance, $\mathrm{CO}_{2}$ and PM10 concentration and wind speed and direction. Incoming short-wave radiation is among the main regulators of urban microclimate. In addition, absolute humidity was reckoned through both monitoring campaigns following the formula of Peci et al.[57]. It is typically measured by a pyranometer facing directly the sky. However, this method is not adequate for accurately depict solar radiation at specific height since it compromises shortwave radiation reflected from surfaces at lower heights. For that reason, the mobile station presented here was equipped with five pyranometers each facing towards a different direction. Similarly, five luxmeters were placed towards different orientations for capturing directional illuminance. In more detail, order to ensure an 
accurate point-wise microclimatic representation of the investigated route, solar global radiation and illuminance are measured each by five different sensors oriented towards (i) the sky, (ii) the street, the (iii) right, the (iv) left and the (v) backside of the vehicle. Furthermore, in order to ensure accurate air temperature profile a corresponding probe is placed in each of the five units. It should be mentioned that in the present study the air temperature probe of unit no. 5 was not utilized. All measurements are taken at the same timestamp every $10 \mathrm{~s}$.

The sensor's main characteristics, such as operation range, accuracy, and sensitivity error are opted for ensuring the desired level of precision of the corresponding variables. All the main technical characteristics of the installed sensors are summarized in Table 5. Furthermore, since the station is mobile, apart from monitoring micrometeorological parameters, data related to the specific position of the sensors are retrieved by a Global Positioning System (GPS) antenna which is also installed on the vehicle. Therefore, all variable measurements can be directly linked with the corresponding latitude, longitude, and altitude with an overall spatial accuracy of $2.5 \mathrm{~m}$. Once the operation was concluded, data loggers of the designed configuration automatically generated a ".csv" file in which all data were saved. Data retrieved from the GPS antenna were also included in the same file and were utilized for intra-urban illustration. Prior to the presented monitoring campaigns, the sensors of the developed instrumentation were calibrated and hence checked for their accuracy. Accurate measurements of air temperature were ensured by aspirating the corresponding sensors by vehicle's motion, and by positioning them inside a specifically designed radiation shield. 
Table 5: Characteristics of the sensors comprised by the station

\begin{tabular}{|c|c|c|c|c|}
\hline Unit & Sensor & Monitored variable & Specifications & Orientation \\
\hline 1 & GMX501 & Tair & $\begin{array}{l}\text { Accuracy : } \pm 0.3{ }^{\circ} \mathrm{C} @ 20{ }^{\circ} \mathrm{C} \\
\text { Resolution: } 0.1{ }^{\circ} \mathrm{C}\end{array}$ & - \\
\hline 1 & GMX501 & $\mathrm{RH}$ & $\begin{array}{l}\text { Accuracy : } \pm 2 \% @ 20^{\circ} \mathrm{C}(10-60 \% \mathrm{RH}) \\
\text { Resolution: } 1 \%\end{array}$ & - \\
\hline 1 & GMX501 & WS & $\begin{array}{l}\text { Accuracy : } \pm 3 \% @ 40 \mathrm{~m} / \mathrm{s} \\
\text { Resolution: } 0.001 \mathrm{~m} / \mathrm{s}\end{array}$ & - \\
\hline 1 & GMX501 & WD & $\begin{array}{l}\text { Accuracy : } \pm 3^{\circ} @ 40 \mathrm{~m} / \mathrm{s} \\
\text { Resolution: } 1^{\circ}\end{array}$ & \\
\hline 1 & GMX501 & $\mathrm{P}$ & $\begin{array}{l}\text { Accuracy : } \pm 0.5 \mathrm{hPa} @ 25^{\circ} \mathrm{C} \\
\text { Resolution: } 0.1 \mathrm{hPa}\end{array}$ & - \\
\hline 1 & GMX501 & $\mathrm{SR}$ & $\begin{array}{l}\text { Spectral range: } 300-3000 \mathrm{~nm} \\
1 \mathrm{~W} / \mathrm{mq}\end{array}$ & upward \\
\hline 1 & DH2021T 8.1 & $\mathrm{E}_{v}$ & Range: $0-10000 \mathrm{~lx}$ & upward \\
\hline 1 & EE820 & $\mathrm{CO}_{2}$ & $\begin{array}{l}\text { Range: } 0-2000 \mathrm{ppm} \\
\text { Accuracy: } \pm(50 \mathrm{ppm}+2 \% \text { of } \\
\text { measured value })\end{array}$ & - \\
\hline 2 & PT100 & Tair & Resolution: $0.1{ }^{\circ} \mathrm{C}$ & - \\
\hline 2 & SR05 & $\mathrm{SR}$ & $\begin{array}{l}\text { Spectral range: } 285-3000 \mathrm{~nm} \\
\text { Calibration uncertainty: }<1.8 \%\end{array}$ & rightward \\
\hline 2 & DH2021T 8.1 & $\mathrm{E}_{v}$ & Range: 0-10000 lx & rightward \\
\hline 3 & PT100 & Tair & Resolution: $0.1{ }^{\circ} \mathrm{C}$ & \\
\hline 3 & SR05 & $\mathrm{SR}$ & $\begin{array}{l}\text { Spectral range: } 285-3000 \mathrm{~nm} \\
\text { Calibration uncertainty: }<1.8 \%\end{array}$ & leftward \\
\hline 3 & DH2021T 8.1 & $\mathrm{E}_{v}$ & Range: $0-10000 \mathrm{~lx}$ & leftward \\
\hline 3 & LCT-12 & PM10 & $\begin{array}{l}\text { Resolution: } 1 / 4096 \\
\text { Accuracy: }<1 \% \\
\end{array}$ & \\
\hline 4 & PT100 & Tair & Resolution: $0.1{ }^{\circ} \mathrm{C}$ & - \\
\hline 4 & SR05 & $\mathrm{SR}$ & $\begin{array}{l}\text { Spectral range: } 285-3000 \mathrm{~nm} \\
\text { Calibration uncertainty: }<1.8 \%\end{array}$ & backward \\
\hline 4 & DH2021T 8.1 & $\mathrm{E}_{v}$ & Range: $0-10000 \mathrm{~lx}$ & backward \\
\hline 5 & SR05 & $\mathrm{SR}$ & $\begin{array}{l}\text { Spectral range: } 285-3000 \mathrm{~nm} \\
\text { Calibration uncertainty: }<1.8 \%\end{array}$ & downward \\
\hline 5 & DH2021T 8.1 & $\mathrm{E}_{v}$ & Range: $0-10000 \mathrm{~lx}$ & downward \\
\hline
\end{tabular}




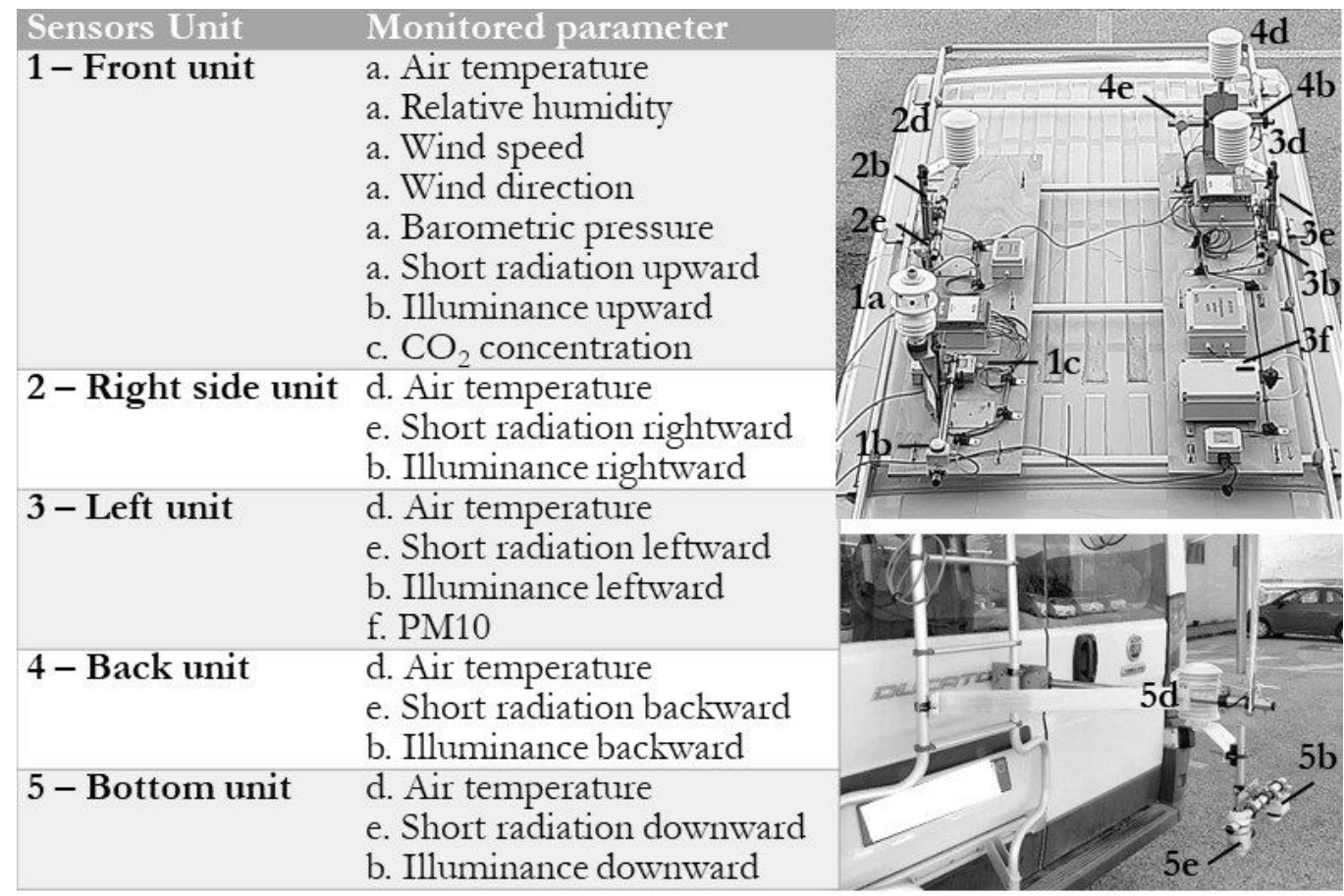

Figure 14: Monitoring system scheme.

\section{Acknowledgment}

Ioannis Kousis's acknowledgments are due to the European Union's Horizon 2020 program under grant agreement No 765057 (SAFERUP) and to the Italian project SOSCITTA. Ilaria Pigliautile's acknowledgments are due to the European Union's Horizon 2020 program under grant agreement No 764025 (Hercules).

\section{Author contributions}

I. Kousis: Methodology, Formal analysis, Investigation, Data curation, Writing - original draft, Writing - review \& editing, Visualization. I. Pigliautile: Conceptualization, Methodology, Software, Formal analysis, Investigation, Data curation, Writing - review \& editing, Visualization, Supervision.A.L. Pisello: Conceptualization, Methodology, Formal analysis, Resources, Writing - review \& editing, Visualization, Supervision, Project administration, Funding acquisition. 


\section{Competing interests}

The authors declare no competing interests.

\section{References}

[1] DESA UN. World urbanization prospects: The 2014 revision. United Nations Department of Economics and Social Affairs, Population Division: New York, NY, USA, 41, 2015.

[2] Aabshar UK Imam and Uttam Kumar Banerjee. Urbanisation and greening of indian cities: Problems, practices, and policies. Ambio, 45(4):442-457, 2016.

[3] Atik Nurwanda and Tsuyoshi Honjo. The prediction of city expansion and land surface temperature in bogor city, indonesia. Sustainable Cities and Society, 52:101772, 2020.

[4] Masoud Ghandehari, Thorsten Emig, and Milad Aghamohamadnia. Surface temperatures in new york city: Geospatial data enables the accurate prediction of radiative heat transfer. Scientific reports, 8(1):1-10, 2018.

[5] Jian Peng, Yaxin Hu, Jianquan Dong, Qianyuan Liu, and Yanxu Liu. Quantifying spatial morphology and connectivity of urban heat islands in a megacity: A radius approach. Science of The Total Environment, $714: 136792,2020$.

[6] Luke Howard. The climate of London, volume 1. W. Phillips, sold also by J. and A. Arch, 1818.

[7] T.R. Oke. City size and the urban heat island. Atmospheric Environment (1967), 7(8):769-779, 1973.

[8] Ioannis Kousis and Anna Laura Pisello. For the mitigation of urban heat island and urban noise island: two simultaneous sides of urban discomfort. Environmental Research Letters, 15(10):103004, 2020.

[9] A John Arnfield. Two decades of urban climate research: a review of turbulence, exchanges of energy and water, and the urban heat island. International Journal of Climatology: a Journal of the Royal Meteorological Society, 23(1):1-26, 2003. 
[10] Kai Gao, Mattheos Santamouris, and Jie Feng. On the cooling potential of irrigation to mitigate urban heat island. Science of The Total Environment, page 139754, 2020.

[11] Elisavet Tsekeri, Dionysia Kolokotsa, and Mat Santamouris. On the association of ambient temperature and elderly mortality in a mediterranean island - crete. Science of The Total Environment, page 139843, 2020.

[12] Somayeh Arghavani, Hossein Malakooti, and Abbas-Ali Ali Akbari Bidokhti. Numerical assessment of the urban green space scenarios on urban heat island and thermal comfort level in tehran metropolis. Journal of Cleaner Production, 261:121183, 2020.

[13] Francesc Baró, Lydia Chaparro, Erik Gómez-Baggethun, Johannes Langemeyer, David J Nowak, and Jaume Terradas. Contribution of ecosystem services to air quality and climate change mitigation policies: the case of urban forests in barcelona, spain. Ambio, 43(4):466-479, 2014.

[14] Peringe Grennfelt, Anna Engleryd, Martin Forsius, Øystein Hov, Henning Rodhe, and Ellis Cowling. Acid rain and air pollution: 50 years of progress in environmental science and policy. Ambio, pages 1-16, 2020.

[15] Xiaoshan Yang, Lilliana L.H. Peng, Zhidian Jiang, Yuan Chen, Lingye Yao, Yunfei He, and Tianjing Xu. Impact of urban heat island on energy demand in buildings: Local climate zones in nanjing. Applied Energy, 260:114279, 2020.

[16] J Roldán-Fontana, R Pacheco-Torres, E Jadraque-Gago, and J Ordóñez. Optimization of co 2 emissions in the design phases of urban planning, based on geometric characteristics: a case study of a low-density urban area in spain. Sustainability Science, 12(1):65-85, 2017.

[17] J. Roxon, F.-J. Ulm, and R.J.-M. Pellenq. Urban heat island impact on state residential energy cost and co2 emissions in the united states. Urban Climate, 31:100546, 2020.

[18] Ronald C Estoque, Makoto Ooba, Xerxes T Seposo, Takuya Togawa, Yasuaki Hijioka, Kiyoshi Takahashi, and Shogo Nakamura. Heat health risk assessment in philippine cities using remotely sensed data and socialecological indicators. Nature communications, 11(1):1-12, 2020. 
[19] Mat Santamouris. Innovating to zero the building sector in europe: Minimising the energy consumption, eradication of the energy poverty and mitigating the local climate change. Solar Energy, 128:61-94, 2016.

[20] Kousis Ioannis, Laskari Marina, Ntouros Vasileios, Assimakopoulos Margarita-Niki, and Romanowicz Joanna. An analysis of the determining factors of fuel poverty among students living in the private-rented sector in europe and its impact on their well-being. Energy Sources, Part B: Economics, Planning, and Policy, pages 1-23, 2020.

[21] Dimitra Founda and Mattheos Santamouris. Synergies between urban heat island and heat waves in athens (greece), during an extremely hot summer (2012). Scientific reports, 7(1):1-11, 2017.

[22] Andri Pyrgou, Panos Hadjinicolaou, and Mat Santamouris. Enhanced near-surface ozone under heatwave conditions in a mediterranean island. Scientific reports, 8(1):9191, 2018.

[23] Andri Pyrgou, Panos Hadjinicolaou, and Mat Santamouris. Urban-rural moisture contrast: Regulator of the urban heat island and heatwaves' synergy over a mediterranean city. Environmental Research, 182:109102, 2020 .

[24] Tsegaye Ginbo, Luca Di Corato, and Ruben Hoffmann. Investing in climate change adaptation and mitigation: A methodological review of real-options studies. Ambio, 2020.

[25] UNFCCC. Establishment of an ad hoc working group on the durban platform for enhanced action, 2011.

[26] Hiroaki Kawase, Akihiko Murata, Ryo Mizuta, Hidetaka Sasaki, Masaya Nosaka, Masayoshi Ishii, and Izuru Takayabu. Enhancement of heavy daily snowfall in central japan due to global warming as projected by large ensemble of regional climate simulations. Climatic Change, 139(2):265$278,2016$.

[27] Andrew Caplin, Masoud Ghandehari, Chris Lim, Paul Glimcher, and George Thurston. Advancing environmental exposure assessment science to benefit society. Nature communications, 10(1):1-11, 2019. 
[28] M. Santamouris. Recent progress on urban overheating and heat island research. integrated assessment of the energy, environmental, vulnerability and health impact. synergies with the global climate change. Energy and Buildings, 207:109482, 2020.

[29] Valentino Sangiorgio, Francesco Fiorito, and Mattheos Santamouris. Development of a holistic urban heat island evaluation methodology. Scientific reports, 10(1):1-13, 2020.

[30] F. Busato, R.M. Lazzarin, and M. Noro. Three years of study of the urban heat island in padua: Experimental results. Sustainable Cities and Society, 10:251 - 258, 2014.

[31] Geun Young Yun, Jack Ngarambe, Patrick Nzivugira Duhirwe, Giulia Ulpiani, Riccardo Paolini, Shamila Haddad, Konstantina Vasilakopoulou, and Mat Santamouris. Predicting the magnitude and the characteristics of the urban heat island in coastal cities in the proximity of desert landforms. the case of sydney. Science of The Total Environment, 709:136068, 2020.

[32] Ilaria Pigliautile and Anna Laura Pisello. A new wearable monitoring system for investigating pedestrians' environmental conditions: Development of the experimental tool and start-up findings. Science of The Total Environment, 630:690 - 706, 2018.

[33] I. Pigliautile and A.L. Pisello. Environmental data clustering analysis through wearable sensing techniques: New bottom-up process aimed to identify intra-urban granular morphologies from pedestrian transects. Building and Environment, 171:106641, 2020.

[34] Shamila Haddad, Riccardo Paolini, Giulia Ulpiani, Afroditi Synnefa, Gertrud Hatvani-Kovacs, Samira Garshasbi, Jonathan Fox, Konstantina Vasilakopoulou, Lawrence Nield, and Mattheos Santamouris. Holistic approach to assess co-benefits of local climate mitigation in a hot humid region of australia. Scientific reports, 10(1):1-17, 2020.

[35] Decheng Zhou, Shuqing Zhao, Liangxia Zhang, Ge Sun, and Yongqiang Liu. The footprint of urban heat island effect in china. Scientific reports, 5(1):1-11, 2015. 
[36] M Santamouris, K Paraponiaris, and G Mihalakakou. Estimating the ecological footprint of the heat island effect over athens, greece. Climatic Change, 80(3-4):265-276, 2007.

[37] Rui Yao, Lunche Wang, Xin Huang, Wenwen Zhang, Junli Li, and Zigeng Niu. Interannual variations in surface urban heat island intensity and associated drivers in china. Journal of Environmental Management, $222: 86-94,2018$.

[38] Decheng Zhou, Stefania Bonafoni, Liangxia Zhang, and Ranghui Wang. Remote sensing of the urban heat island effect in a highly populated urban agglomeration area in east china. Science of The Total Environment, 628-629:415 - 429, 2018.

[39] Melissa A Hart and David J Sailor. Quantifying the influence of land-use and surface characteristics on spatial variability in the urban heat island. Theoretical and applied climatology, 95(3-4):397-406, 2009.

[40] M. Santamouris, N. Gaitani, A. Spanou, M. Saliari, K. Giannopoulou, K. Vasilakopoulou, and T. Kardomateas. Using cool paving materials to improve microclimate of urban areas - design realization and results of the flisvos project. Building and Environment, 53:128 - 136, 2012.

[41] Tammy E Parece, Jie Li, James B Campbell, and David Carroll. Assessing urban landscape variables' contributions to microclimates. Advances in Meteorology, 2016, 2016.

[42] M. Santamouris, R. Paolini, S. Haddad, A. Synnefa, S. Garshasbi, G. Hatvani-Kovacs, K. Gobakis, K. Yenneti, K. Vasilakopoulou, J. Feng, K. Gao, G. Papangelis, A. Dandou, G. Methymaki, P. Portalakis, and M. Tombrou. Heat mitigation technologies can improve sustainability in cities. an holistic experimental and numerical impact assessment of urban overheating and related heat mitigation strategies on energy consumption, indoor comfort, vulnerability and heat-related mortality and morbidity in cities. Energy and Buildings, 217:110002, 2020.

[43] RA Spronken-Smith and TR Oke. The thermal regime of urban parks in two cities with different summer climates. International journal of remote sensing, 19(11):2085-2104, 1998. 
[44] Iain Douglas Stewart. Influence of meteorological conditions on the intensity and form of the urban heat island effect in regina. Canadian Geographer/Le Géographe canadien, 44(3):271-285, 2000.

[45] Blagovesta Dimitrova, Milena Vuckovic, Kristina Kiesel, Ardeshir Mahdavi, and B Ecology. Trees and the microclimate of the urban canyon: A case study. In Proceedings of the 2nd ICAUD International Conference in Architecture and Urban Design, Tirana, Albania, 2014.

[46] Yasuyo Makido, Vivek Shandas, Salim Ferwati, and David Sailor. Daytime variation of urban heat islands: the case study of doha, qatar. Climate, 4(2):32, 2016.

[47] Ali Soltani and Ehsan Sharifi. Daily variation of urban heat island effect and its correlations to urban greenery: A case study of adelaide. Frontiers of Architectural Research, 6(4):529 - 538, 2017.

[48] Haider Taha, Ronnen Levinson, Arash Mohegh, Haley Gilbert, George Ban-Weiss, and Sharon Chen. Air-temperature response to neighborhoodscale variations in albedo and canopy cover in the real world: Fineresolution meteorological modeling and mobile temperature observations in the los angeles climate archipelago. Climate, 6(2):53, 2018.

[49] Yoo-Jun KIM, Baek-Jo KIM, Yoon-Sook SHIN, Hui-Won KIM, Geon-Tae KIM, and Seon-Jeong KIM. A case study of environmental characteristics on urban road-surface and air temperatures during heat-wave days in seoul. Atmospheric and Oceanic Science Letters, 12(4):261-269, 2019.

[50] Chen-Yi Sun, Soushi Kato, and Zhonghua Gou. Application of lowcost sensors for urban heat island assessment: A case study in taiwan. Sustainability, 11(10):2759, 2019.

[51] Cor Jacobs, Tanya Singh, Ganesh Gorti, Usman Iftikhar, Salar Saeed, Abu Syed, Farhat Abbas, Bashir Ahmad, Suruchi Bhadwal, and Christian Siderius. Patterns of outdoor exposure to heat in three south asian cities. Science of The Total Environment, 674:264 - 278, 2019.

[52] Laura Romero Rodríguez, José Sánchez Ramos, Francisco José Sánchez de la Flor, and Servando Álvarez Domínguez. Analyzing the urban heat island: Comprehensive methodology for data gathering and optimal 
design of mobile transects. Sustainable Cities and Society, 55:102027, 2020 .

[53] Carolina Vasilikou and Marialena Nikolopoulou. Outdoor thermal comfort for pedestrians in movement: thermal walks in complex urban morphology. International journal of biometeorology, 64(2):277-291, 2020 .

[54] M. Santamouris. Using cool pavements as a mitigation strategy to fight urban heat island - a review of the actual developments. Renewable and Sustainable Energy Reviews, 26:224 - 240, 2013.

[55] Milena Vuckovic, Kristina Kiesel, and Ardeshir Mahdavi. The extent and implications of the microclimatic conditions in the urban environment: A vienna case study. Sustainability, 9(2):177, 2017.

[56] Ioannis Kousis, Claudia Fabiani, Laura Gobbi, and Anna Laura Pisello. Phosphorescent-based pavements for counteracting urban overheating a proof of concept. Solar Energy, 202:540 - 552, 2020.

[57] Adriana Peci, Anne-Luise Winter, Ye Li, Saravanamuttu Gnaneshan, Juan Liu, Samira Mubareka, and Jonathan B Gubbay. Effects of absolute humidity, relative humidity, temperature, and wind speed on influenza activity in toronto, ontario, canada. Applied and environmental microbiology, 85(6), 2019. 


\section{Figures}

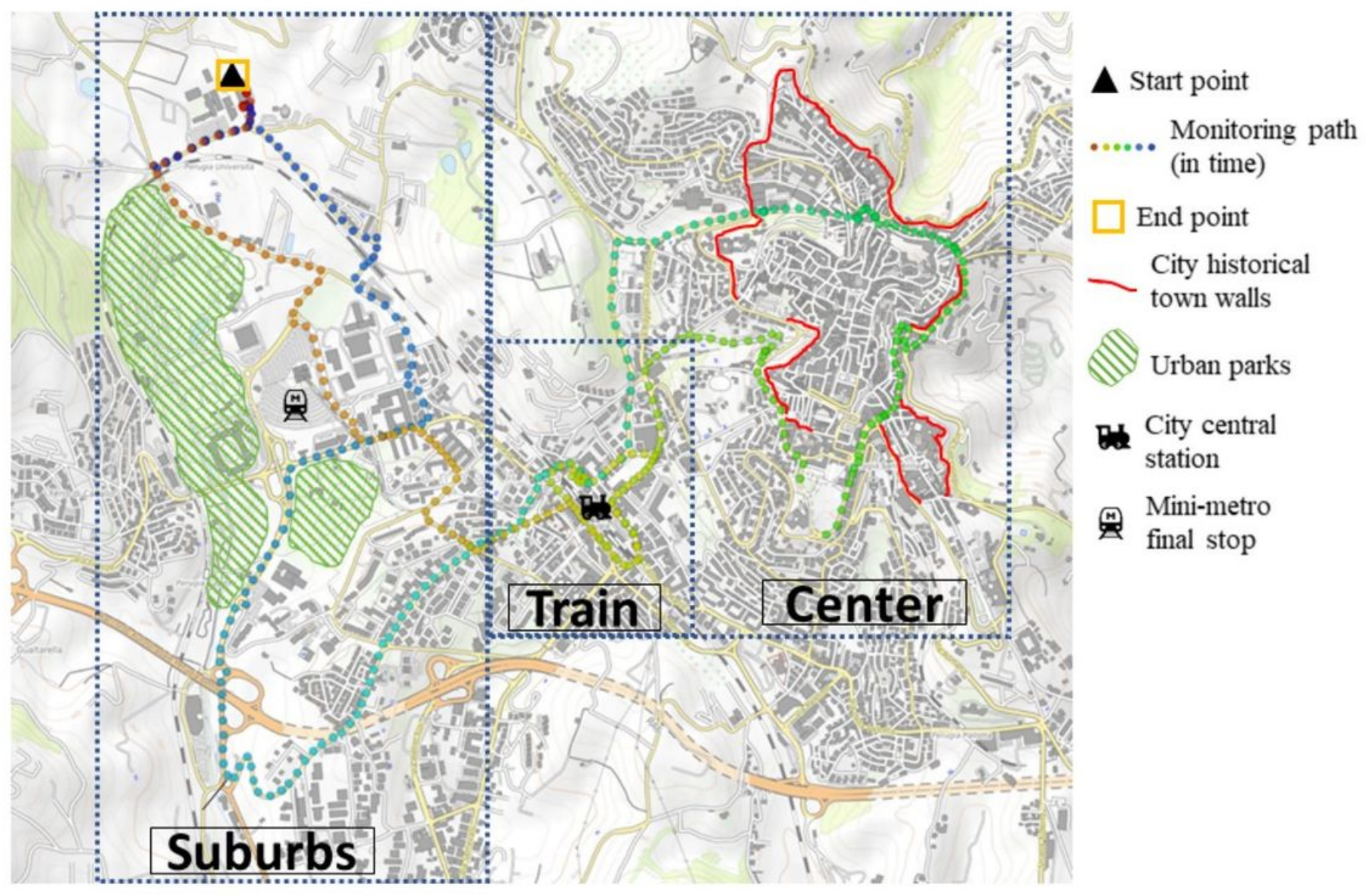

Figure 1

Pathway of monitoring campaigns. Note: The designations employed and the presentation of the material on this map do not imply the expression of any opinion whatsoever on the part of Research Square concerning the legal status of any country, territory, city or area or of its authorities, or concerning the delimitation of its frontiers or boundaries. This map has been provided by the authors. 

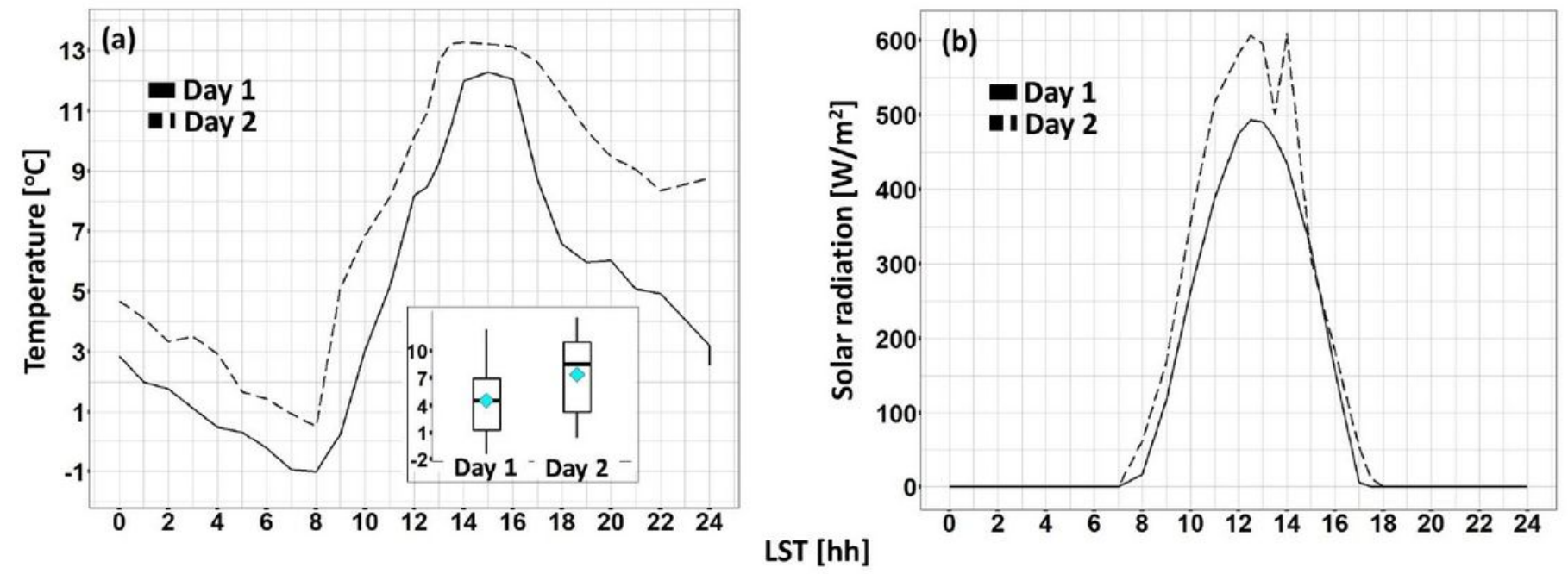

Figure 2

(a) $24 \mathrm{~h}$ air temperature profile for both day-1 and day-2, (b) $24 \mathrm{~h}$ solar global radiation profile for both day-1 and day-2 

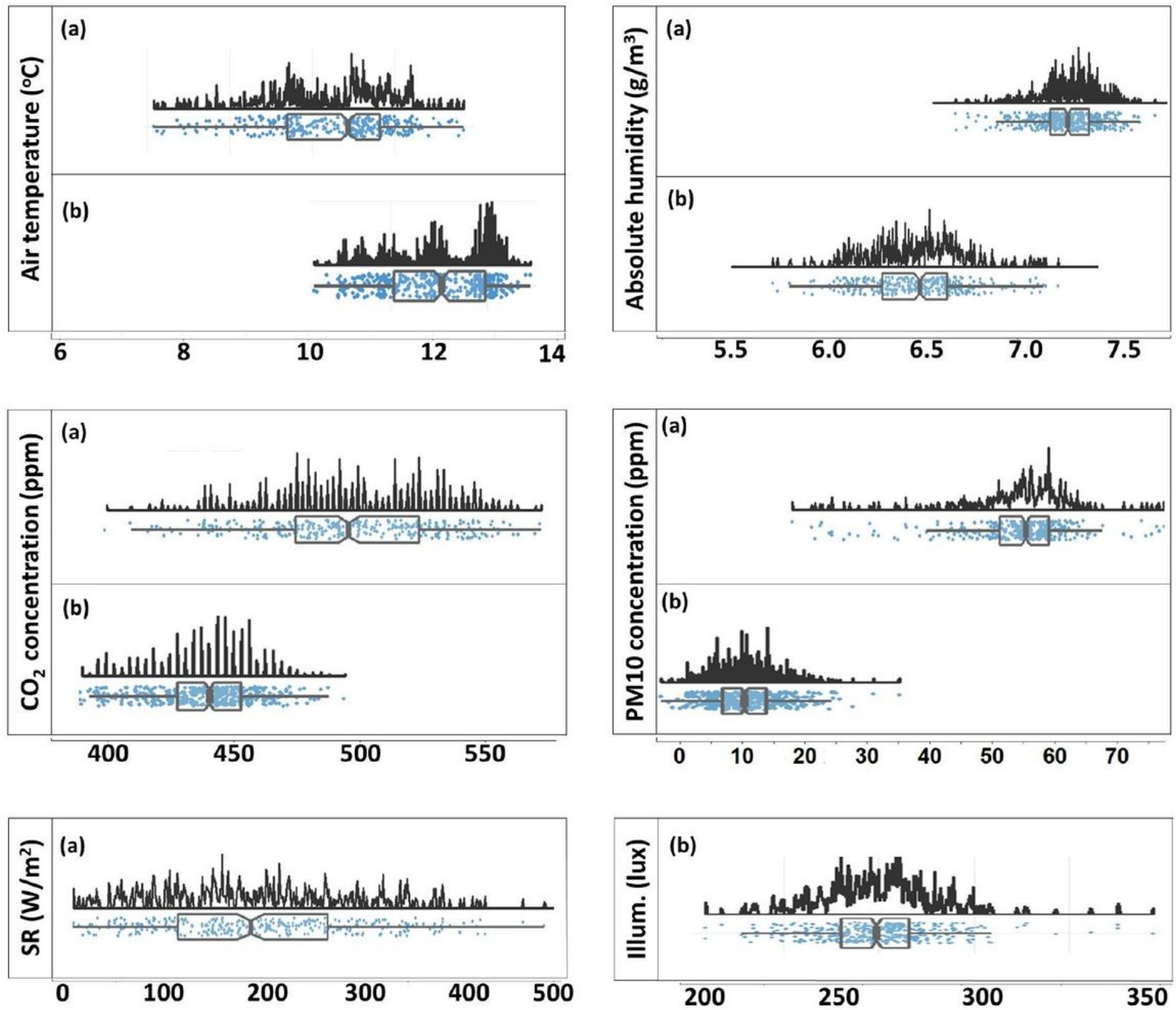

Figure 3

Variables' distribution.(a) day 1, (b) day 2. 

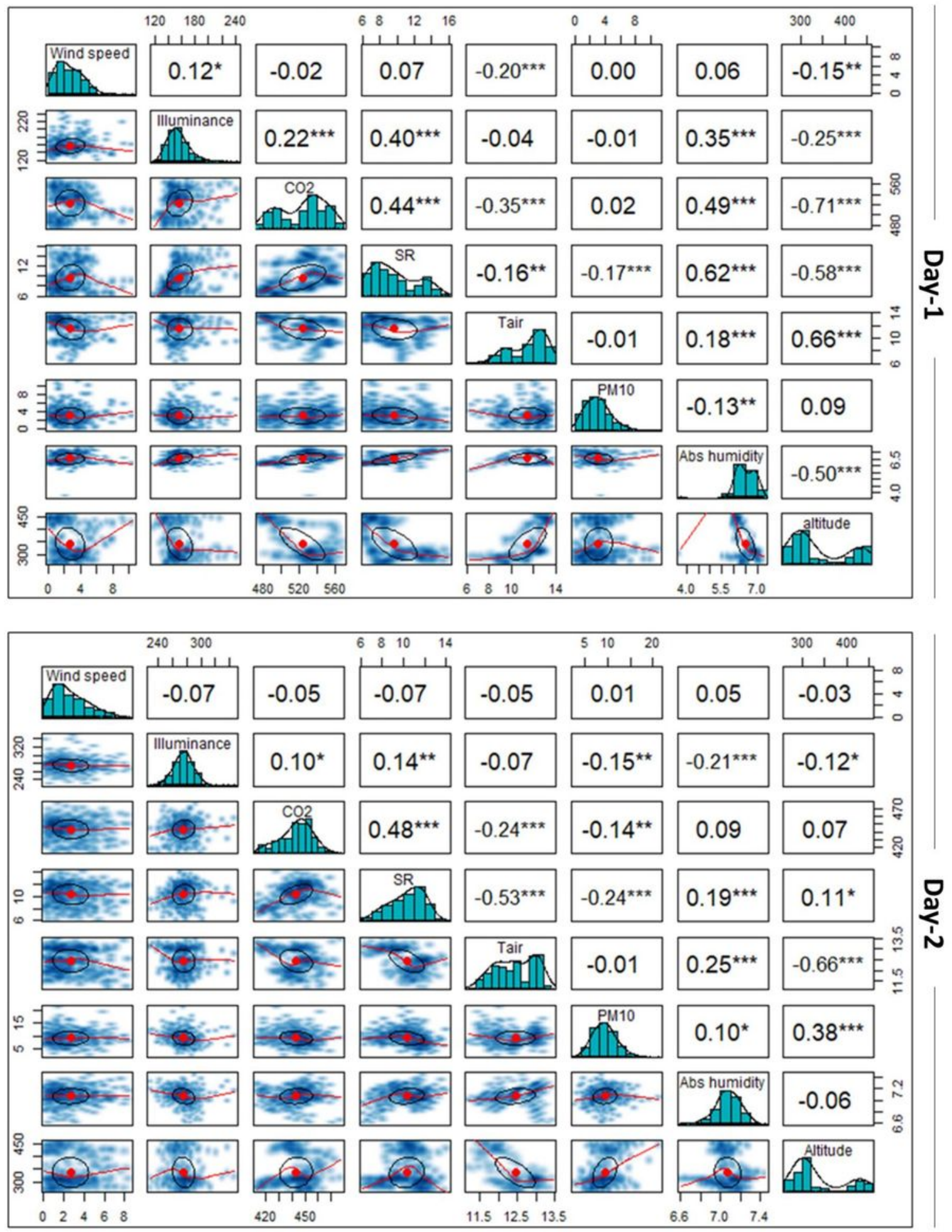

Figure 4

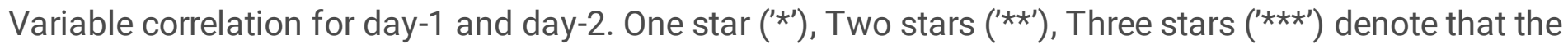
corresponding variable is significant at $10 \%, 5 \%, 1 \%$ level, respectively. Absence of star denotes no significant variable. 

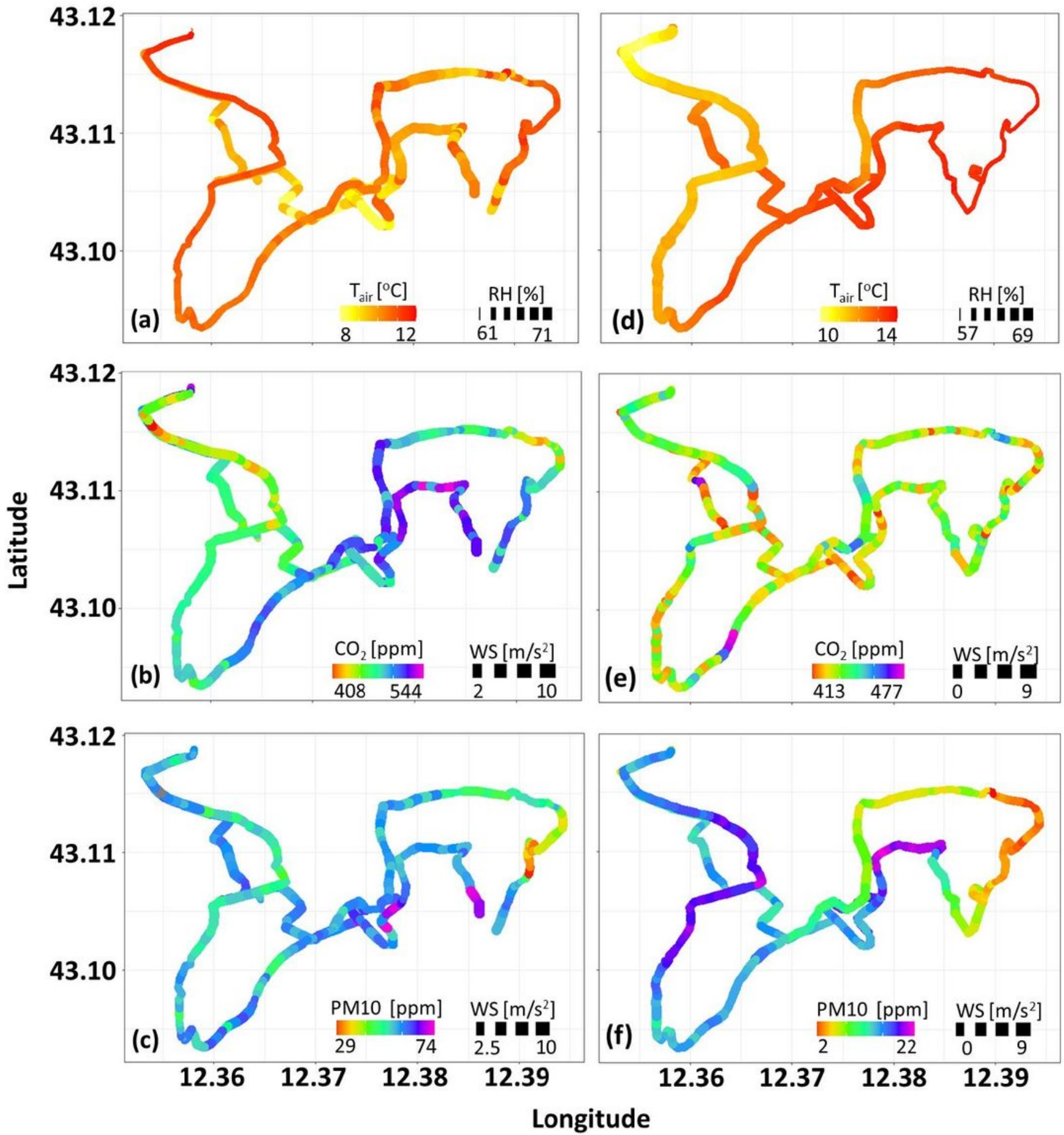

Figure 5

Day-time/Evening-time monitoring. (a) day 1 - air temperature vs. relative humidity, (b) day 1 - CO2 concentration vs. wind speed, (c) day 1 - PM10 concentration vs. wind speed, (d) day 2 - air temperature vs. relative humidity, (e) day 2 - CO2 concentration vs. wind speed, (f) day 2 - PM10 concentration vs. wind speed 


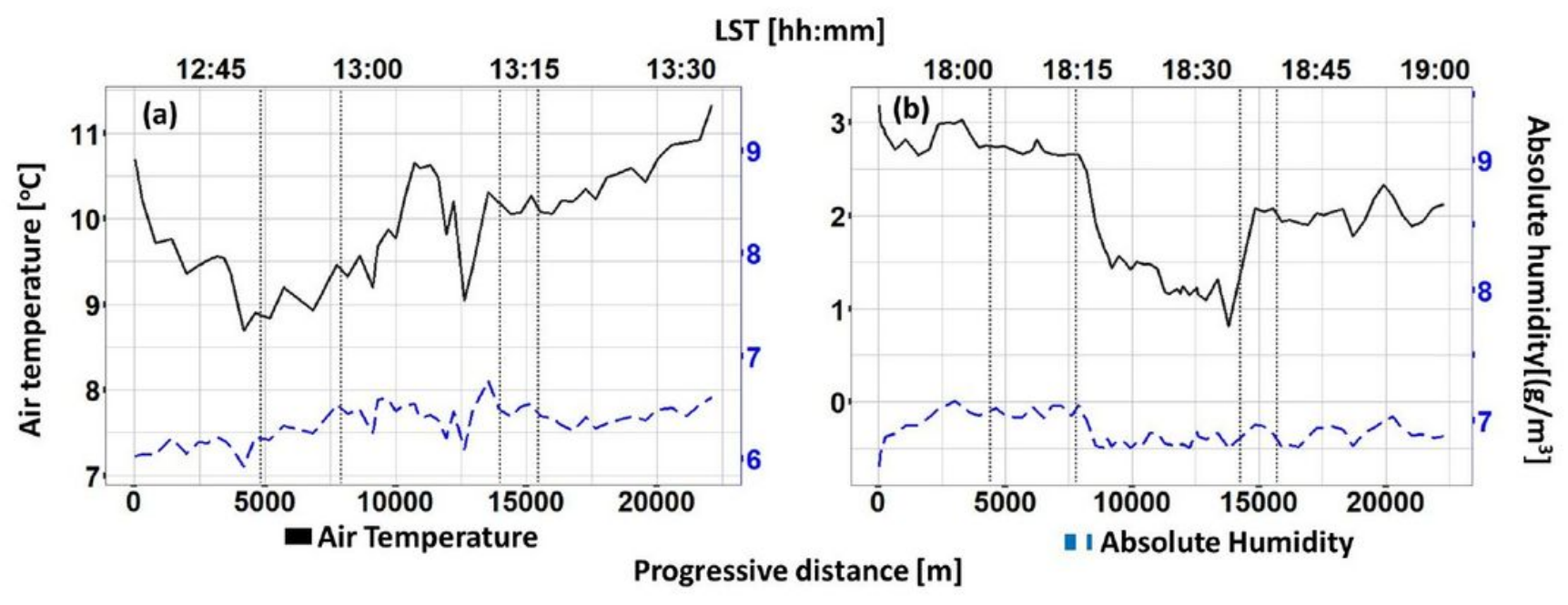

Figure 6

Air temperature and absolute humidity for (a) day 1, (b) day 2 monitoring. Vertical dotted lines stand for the boundaries in-between suburban (first and fifth section), train (second and forth section) and center area of the city.

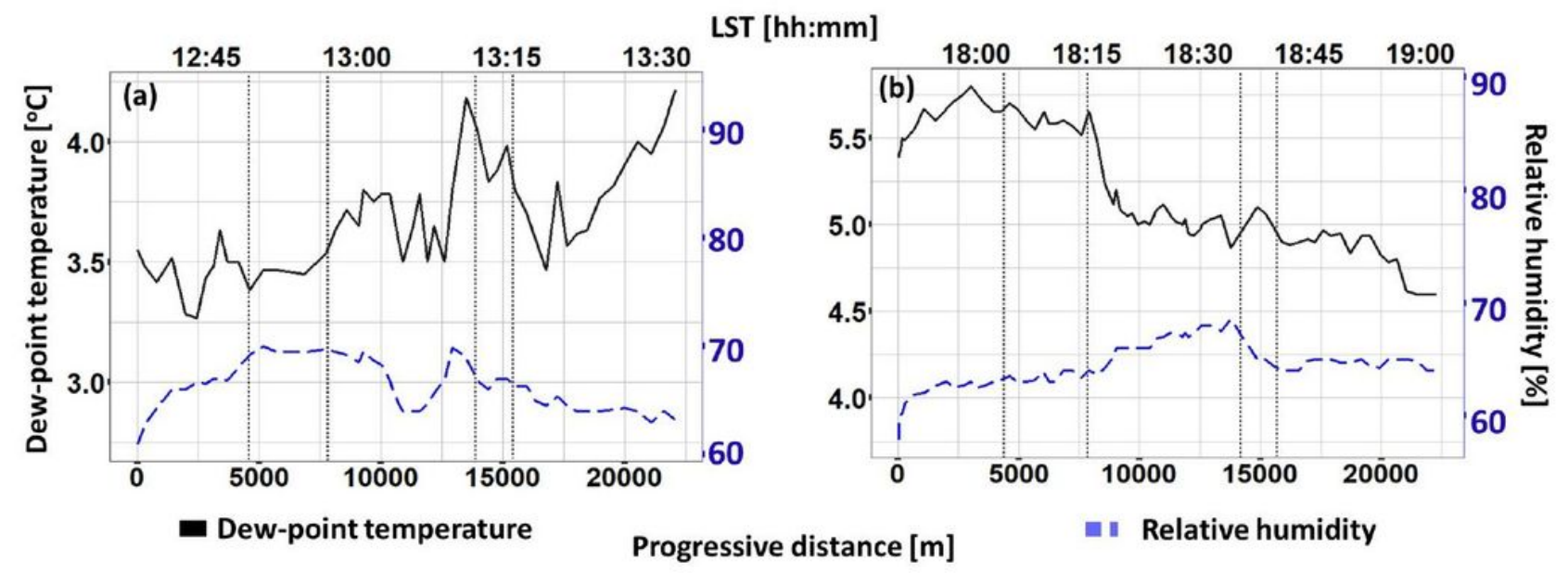

\section{Figure 7}

Dew-point temperature and relative humidity (a) day 1, (b) day 2 monitoring. Vertical dotted lines stand for the boundaries in-between suburban (first and fifth section), train (second and forth section) and center area of the city. 


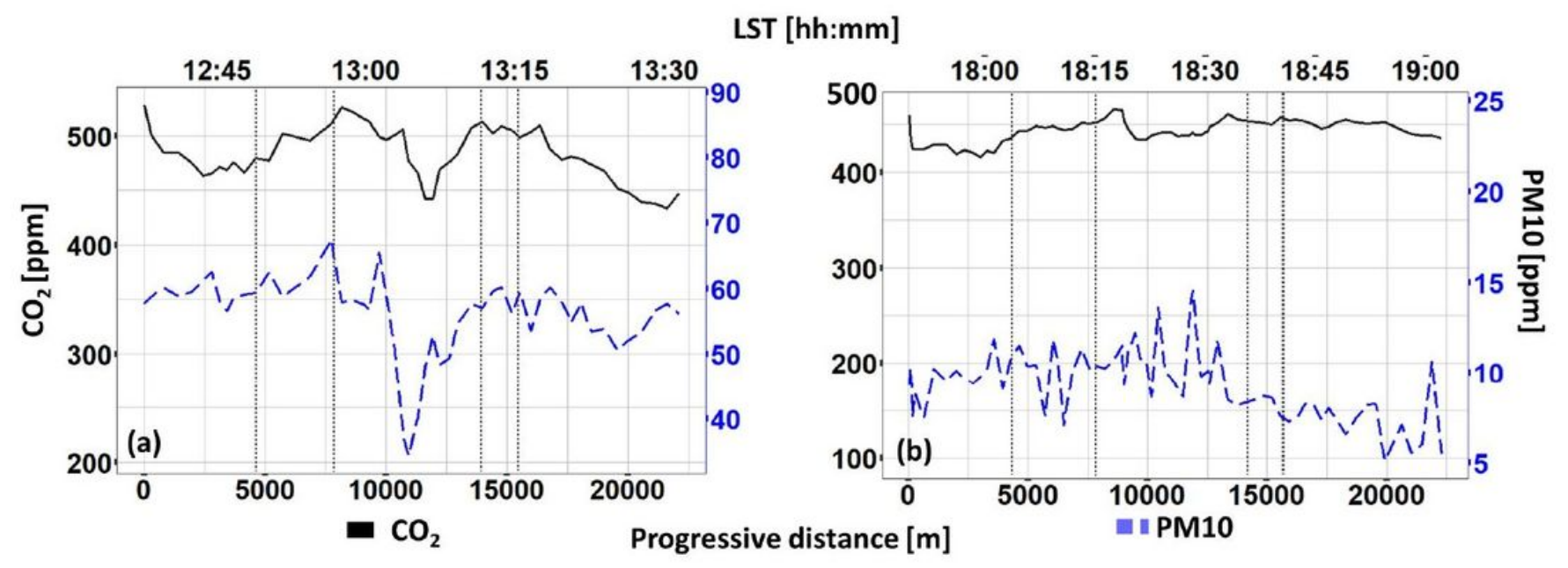

Figure 8

CO2 and PM10 concentration (a) day 1, (b) day 2 monitoring. Vertical dotted lines stand for the boundaries in-between suburban (first and fifth section), train (second and forth section) and center area of the city.

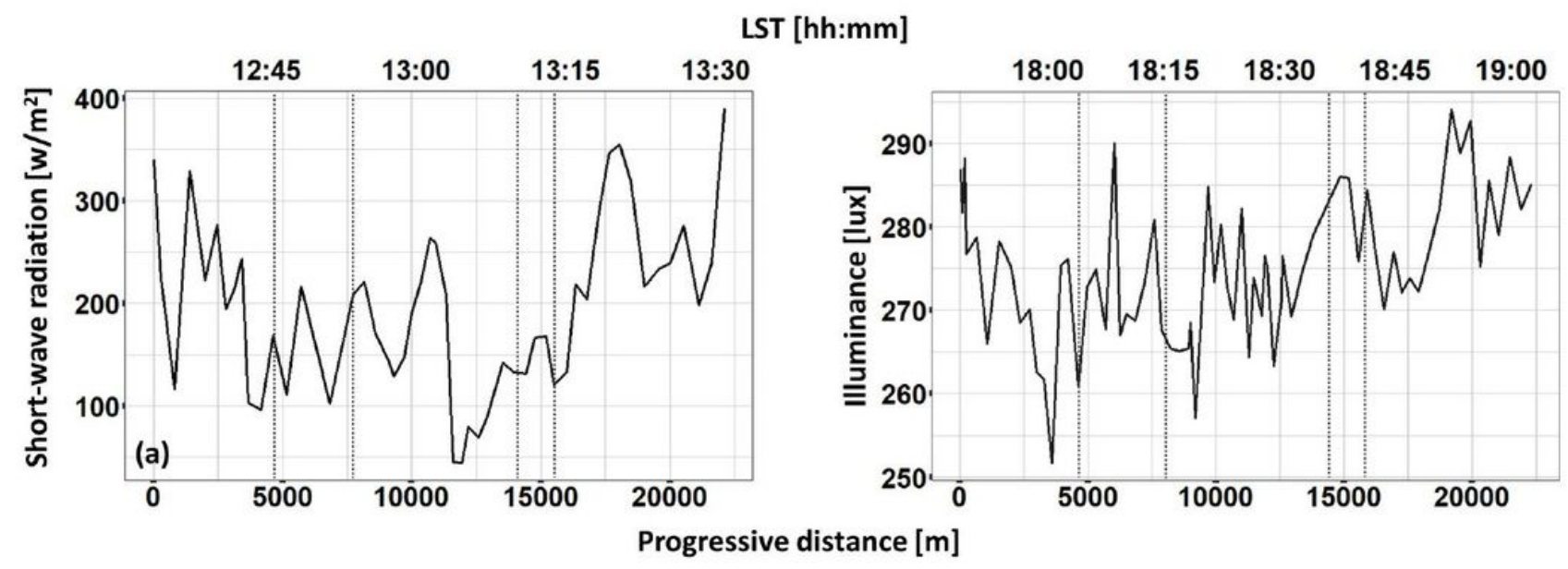

Figure 9

Solar-wave radiation and illuminance (a) day 1, (b) day 2 monitoring. Vertical dotted lines stand for the boundaries in-between suburban (first and fifth section), train (second and forth section) and center area of the city. 


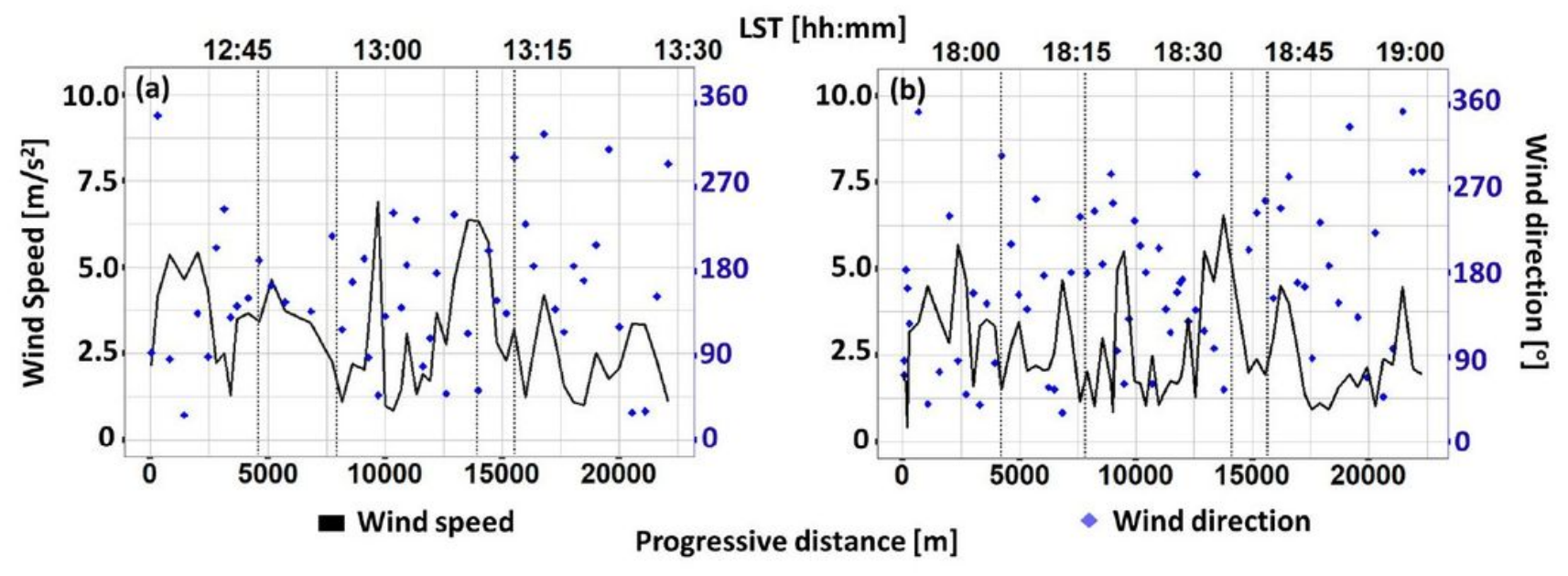

Figure 10

Wind speed and direction (a) day 1, (b) day 2 monitoring. Vertical dotted lines stand for the boundaries inbetween suburban (first and fifth section), train (second and forth section) and center area of the city.

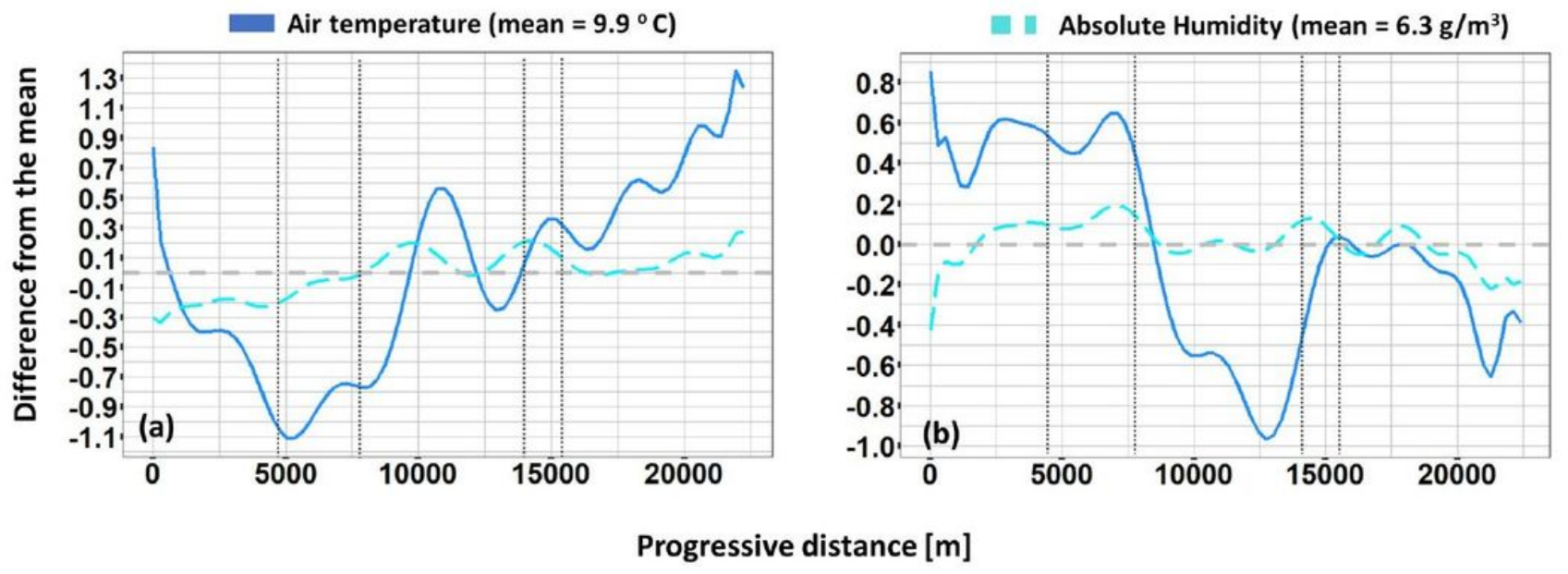

Figure 11

Deviations from the mean value. (a) day 1 - air temperature and absolute humidity, (b) day 2 - air temperature and absolute humidity. Vertical dotted lines stand for the boundaries in-between suburban (first and fifth section), train (second and forth section) and center area of the city. 

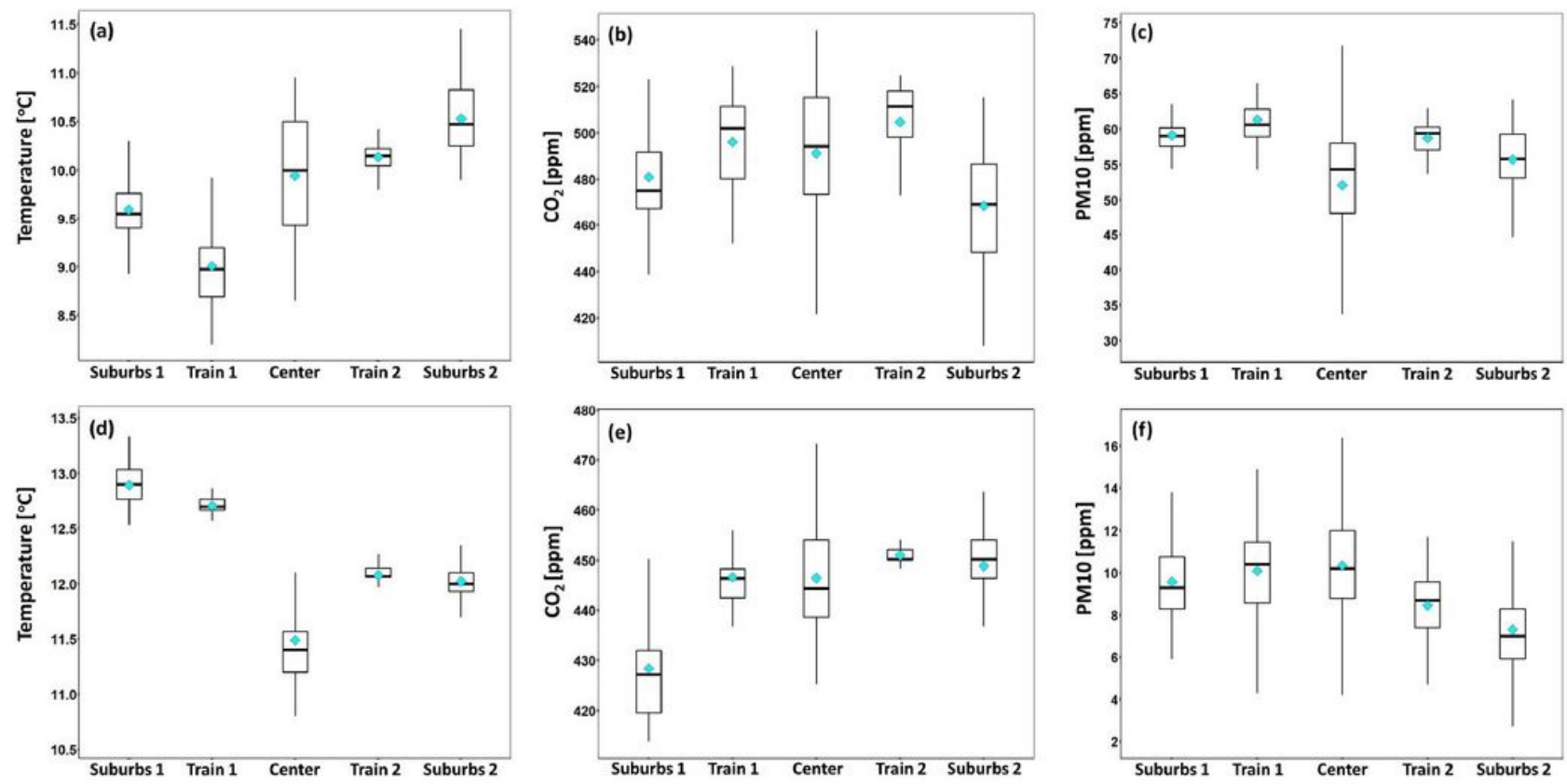

\section{Figure 12}

Cluster analysis of air temperature and air pollutants. 